This dissertation has been

microfilmed exactly as received $\quad 68-11,943$

ZAYE, David F., 1940-

CATION ANALYSIS BY THIN-LAYER CHROMATOGRAPHY AND REFLECTANCE SPECTROSCOPY.

University of Hawaii, Ph.D., 1968

Chemistry, analytical

University Microfilms, Inc., Ann Arbor, Michigan 


\title{
CATION ANALYSIS BY THIN-LAYER CHROMATOGRAPHY AND REFLECTANCE SPECTROSCOPY
}

\section{A DISSERTATION SUBMITTED TO THE GRADUATE DIVISION OF THE UNIVERSITY OF HAWAII IN PARTIAL FULFILLMENT \\ OF THE REQUIREMENTS FOR THE DEGREE OF \\ DOCTOR OF PHILOSOPHY \\ IN CHEMISTRY \\ JANUARY 1968}

\author{
By \\ David F. Zaye
}

\author{
Dissertation Committee: \\ Harry Zeitlin, Chalrman \\ Robert A. Duce \\ Richard G. Inskeep \\ Sidney J. Townsley \\ Jay W. Wrathall
}


ABSTRACT

A procedure whereby reflectance spectroscopy can be employed for the analysis of substances resolved on thinlayer plates was developed with the use of metal cation mixtures that had been separated on cellulose plates. A rapid method was devised whereby fourteen cations were separated and identified in situ by their reflectance spectra after chromogenesis with a mixture of dithizone and 8-hydroxyquinoline.

Further studies were carried out on three of these cations: copper, nickel, and zinc. Copper and nickel were determined in the presence of eleven other cations without experiencing any interferences by employing neocuproine and dimethylglyoxime, respectively, as chromogenic reagents. In the case of zinc, the use of 3,3'-dimethylnaphthidine was equaliy successful except in the presence of tin, cadmium, and iron. The optimum concentration and reflectance ranges and the maximum accuracy of these analyses were then deduced by applying two graphical methods to the data obtalned.

A high-reflectance differential technique was developed for the measurement of micromamounts of the above three cations. As the concentration of the reflectance standard was decreased, the lower limits of both the optimum reflectance range and optimum concentration range was extended to lower values. The probable percent error 
arising from an error of $1 \%$ reflectance was decreased significantly from $7 \%$ in the "ordinary"method to approximetly 2-3\% with the use of approprtate differential standards.

Finally the utility of the procedure in the analysis of sea water was demonstrated. Precencentration of the trace metals was carried out using dithizone as the sequestering reagent. After back-extraction into the aqueous phase, the copper, nickel, and zinc were separated from each other and from interferences on cellulose chromatoplates. The were then determined by the methods developed employing both the ordinary and high reflectance techniques. The experimental methods were evaluated by enriching sea water samples with the three metal cations and carrying through the extraction, chromatographic separation, and reflectance measurements. 
TABLE OF CONTENTS

Page

Abstract

List of Tables

vi i

List of Illustrations

viii

Introduction

Experimental

A. The rapid identification of cations resolved on thin-layer plates

B. The determination of copper, nickel, and zinc

C. Differential reflectance spectroscopy.
A high reflectance method

D. The application of reflectance spectroscopy to the analysis of some trace metal cations in sea water

Results and Discussion

A. The rapid identification of cations resolved on thin-layer plates

B. The determination of copper, nickel, and zinc

C. Differential reflectance spectroscopy. A high reflectance method

D. The application of reflectance spectroscopy to the analysis of some trace metal cations in sea water 
Bibliography 


\section{LIST OF TABLES}

Table

I. $R_{f}$ values and spectral data for cations adsorbed on MN-cellulose

II. $R_{f}$ values and color reactions obtained for cations adsorbed on MN-cellulose

III. Optimum range and probable error in the determination of cations adsorbed on MN-cellulose

IV. Reproducibility of \% reflectance obtained for replicate samples of cations adsorbed on MNcellulose

V. Optimum percent reflectance and concentration ranges for analysis and percent error

VI. Determination of copper, nickel, and zinc in $300 \mathrm{ml}$ sea water employing the ordinary method of reflectance spectroscopy

VII. Determination of copper, nickel, and zinc in $300 \mathrm{ml}$ enriched sea water employing the ordinary method of reflectance spectroscopy

VIII. Determination of copper, nickel, and zinc in sea water employing the high reflectance method of differential spectroscopy

IX. Determination of copper, nickel, and zinc in enriched sea water employing the high reflectance method of differential spectroscopy 


\section{LIST OF ILLUSTRATIONS}

Figure

1. (A) Dimensions of cell elements and sketch of assembled windowless cell (B) Tamp used to pack cell

2. Reflectance spectra obtained for $10 \mu g$ of chromium, lead, and silver cations adsorbed on cellulose after chromatoplates had been sprayed with dithizone-oxine reagent

3. Reflectance spectra obtained for $10 \mu g$ of chromium, lead, and silver cations adsorbed on cellulose after chromatoplates had been sprayed with dithizone-oxine reagent and subsequently exposed to ammonia fumes

4. Reflectance spectra of $5 \mu g$ of cobalt and zinc cations adsorbed on cellulose after thin-layer plates had been sprayed with dithizone-oxine reagent. Cobalt and zinc spectra obtained by direct measurement contrasted with cobalt and zinc spectra obtained with the use of reflectance celis

5. Reflectance spectra obtained for $0.1 \mu g-a t$ of copper, nickel, and zinc cations adsorbed on cellulose and sprayed with the appropriate chromogenic reagent

6. Percent reflectance at the absorption maxima of the colored products formed by copper, nickel and 
zinc as a function of the logarithm of the concentration of the cation

7. Percent reflectance at $540 \mathrm{m \mu}$ of nickel-dimethylglyoxime adsorbed on cellulose as a function of concentration

8. Percent reflectance at $448 \mathrm{~m} \mu$ of copper-neocuproine adsorbed on cellulose as a function of concentration

9. Percent reflectance at $565 \mathrm{~m} \mu$ of zinc-naphthi dine compound adsorbed on cellulose as a function of concentration

10. $\left[(1-p)\left(1-R_{h}\right)\right]^{2} /\left(R_{h}(1-p)+p\right)$ vs. concentration for nickel-dimethylglyoxime complex adsorbed on cellulose

11. $\left[(1-p)\left(1-R_{h}\right)\right]^{2} /\left(R_{h}(1-p)+p\right)$ vs. concentration for copper-neocuproine complex adsorbed on cellulose

12. $\left[(1-p)\left(1-R_{h}\right)\right]^{2} /\left(R_{h}(1-p)+p\right)$ vs. concentration for zinc naphthidine compound adsorbed on cellulose

13. Percent exror as a function of percent reflectance

14. Percent error arising from an error of $1 \% R$, computed with the use of equation (12), as a function of percent reflectance for nickel- 
dimethylglyoxime adsorbed on cellulose

15. Percent error arising from an error of $1 \% \mathrm{R}$, computed with the use of equation (12), as a function of percent reflectance for copperneocuprolne adsorbed on cellulose

16. Percent error arising from an error of $1 \% R$, computed with the use of equation (12), as a function of percent refiectance for zincnaphthidine adsorbed on cellulose

17. Percent error arising from an error of $1 \% R$ (estimated graphicaliy) as a function of percent reflectance for nickel-dimethylglyoxime adsorbed on cellulose

18. Percent error arising from an error of $1 \% R$ (estimated graphically) as a function of percent reflectance for copper-neocuprolne adsorbed on cellulose

19. Percent error arising from an error of $1 \% R$ (estimated graphically) as a function of Percent reflectance for zinc-naphthidine adsorbed on cellulose

20. Kubelka-Munk values at $448 \mathrm{~m} \mu$ for copper neocuproine adsorbed on cellulose as a function of concentration employing a $5 \mu \mathrm{g} \mathrm{Cu} / 40 \mathrm{mg}$ cellulose reference standard 
21. Kubelka-Munk values at $540 \mathrm{~m} \mu$ for nickeldimethylglyoxime adsorbed on cellulose as a function of concentration employing a $5 \mu g$ $\mathrm{NI} / 40 \mathrm{mg}$ cellulose reference standard

22. Kubelka-Munk values at $565 \mathrm{mp}$ for zincnaphthidine adsorbed on cellulose as a function of concentration employing a $20 \mu g$ $\mathrm{Zn} / 40 \mathrm{mg}$ cellulose reference standard 


\section{INTRODU CTION}

There are few, if any, inorganic chemical systems of importance that are entirely unique to a single chemical species; rather the properties measured are generally characteristic of a number of elements. Thus a scheme must be devised for isolating the species of interest from all others present in the original material. Thin-layer chromatography has shown promise as a means of separating Inorganic cations; the technique is simple, rapid, and sensitive. Often the separations achieved are sharper than those achieved with similar solvent systems on columns and paper.

The analytical utility of thin-layer chromatography has been enhanced by employing it in conjunction with spectral reflectance. In situ identification and determination of resolved species can be accomplished by means of reflectance measurements carried out on various compounds resolved on thin-layer chromatograms. It is the aim of this research to extend the application of this technique to the separation and analysis of inorganic cations. By employing a differential modification to spectral reflectance, the utility of the method could be extended to the determination of low concentrations with greater precision in the measurement. This would be particularly suitable to the analysis of a mixture such as trace metal cations in sea water following thelr resolution 
by thin-layer chromatography•

The use of thin-layers of adsorbent for the separation of materials was used as early as 1938,1 but Meinhard and Hall ${ }^{2}$ were the first to develop a stable layer and showed how a mixture of zinc and iron (III) salts could be separated. Because their results were not satisfactory, the thin-layer chromatographic technique for separation of cations was very $11 \mathrm{mited}$. Indeed, the field was ignored until 1960 when Seller and Seiler, ${ }^{3}$ using silica gel layers separated a mixture of mercury, cadmium, bismuth, lead, and copper using a solvent mixture of butanol, hydrochloric acid, and acetonylacetone. Replacing the butanol with methanol, they separated nickel, cobalt, zinc, manganese, lead, aluminum, chromium, and iron. Sample concentrations as small as $2 \times 10^{-7} \mathrm{M}$ could be detected, and development time was shorter than that encountered in paper chromatography. Seiler 4 also chromatographed copper, cobalt, and nickel in a series of organic solvents containing $10 \%$ hydrochloric acid or $10 \%$ perchloric acid to study the factors influencing migration rates. He found that the relative order of the $R_{f}$ values depended upon the organic solvents when perchloric acid was used, but with hydrochloric acid the order was usually copper, cobalt, and nickel in decreasing order. Goller ${ }^{5}$ developed a simple, rapid procedure for the separation of elght cations using alumina thin- 
layers. The developing solvent consisted of a $1: 1$ mixture $0.5 \mathrm{M}$ bromide ton in $1 \mathrm{M}$ hydrochloric acid-isopropyl alcohol; and the resolution was attained in 90 minutes. Using both alumina and silica gel, Hashmi et al. ${ }^{6}$ identifled 40 cations by circular thin-layer chromatography. The ions were extracted into groups prior to separation and a total of five difterent solvent systems was employed. Each of these publications pointed up the advantages accruing to the use of thin-layer chromatography: shorter development time, simple and rapid preparation of the plates, use of small samples, and sharper delineation of the resolved species. The analytical utility of thinlayer chromatography for the separation of inorganic tons was further emphasized by Randerath ${ }^{7}$ in that it is generally possible to adopt the procedures of separation that have been worked out for paper chromatography with little or no modification.

Most of the procedures for the chromatographic separation of cations prior to 1960 employed paper as the substrate, and extensive work has been done in this area. However, many of the procedures discussed in the publications pertalned to separztions of groups of metals, either in conjunction with schemes of analysis or simply to solve a specific problem. For the separation of Group I metals, Frierson and Ammons ${ }^{8}$ recommended the use of butanol saturated with acetic acid; and Pollard and coworkers ${ }^{9}$ 
separated lead, silver, and mercury using butanol saturated with nitric acid. Lederer ${ }^{10}$ suggested that Group 2 metals inay be resolved on paper by employing butanol saturated with $1 \mathrm{~N}$ hydrochloric acid, and a similar scheme was also used by Reeves and Crumpler. 11 Numerous solvents give good separations of arsenic and antimony, but relatively few good separations of antimong and $t i n$ have been reported. However, good separations of all chree metals may be obtained with collidine and nitric acid, 12 or by the use of simple alcohols with hydrochloric acid. 13 For Groups 4 and 5, Burstall et al. ${ }^{14}$ recommended acetic acid containing methanol to separate a infture of iron, aluminum, and chromium chlorides. For iron, cobalt, nicke1, and manganese, Burstall et al ${ }^{15}$ achieved good separations with low molecular weight ketones contalning water and hydrochloric acid. Acetone, water, and hydrochloric acid were also used to separate a mixture of copper, nickel, manganese, and zinc. 14

The identification of the cations, whether resolved on paper or thin-layers of adsorbent, most generally involves the use of suitable chromogenic reagents. The most common reagent used for this has been hydrogen sulfide $3,5,10$ which gives the characteristically colored precipitates. If the paper is exposed to ammonia prior to treatment with hydrogen sulfide, the number of metals made visible increases. A number of organtc cheiating 
compounds have al so been employed. Elbeih and coworkers, ${ }^{12}$ after spraying with a mixture of kojlc acid and 8-hydroxyquinoline and subsequent ammonia treatment, viewed the chromatogram under ultraviolet $11 \mathrm{ght}$. Because of fluorescence and quenching, they reported the identification of twenty cations. A similar techinique was described by Reeves and Crumpler ${ }^{11}$ who used diphenylcarbazide and resorcinol as well as 8-hydroxyquinoline. The paper chromatograms were examined in visible as well as ultraviolet light. Other chromogenic reagents which have been successfully employed are dimethylglyoxime, ${ }^{5,6}$ dithizone, 6,14 and rebeanic acid. 6,14 Although a mixture of chromogenic reagents is usually superior to a single one, a specific spray reagent has been employed for each ion under investigation. 6 In such cases it is usually necessary to run a separate chromatogram for each spray reagent. However, problems arise when two or more cations have the same $R_{f}$ value when chromatographed. The values would be undependable for identification purposes, parm ticularly if the chromogentc reagent was a non-specific one such as hydrogen sulfide where many lons give simply a black color. Another method would have to be found for the qualitative determination of these ions.

The methods employed in the quantitative evaluation of the paper and thin-layer chromatograms have also paralleled. Removing the species of interest from the 
adsorbent and then determining it by some conventional means has been used successfully. Lacourt and coworkers ${ }^{16,17}$ separated and analyzed five metals colorimetrically from paper chromatograms, and similar methods were employed by Kember and Wells. 18 Lewis and Griffiths 19 suggested using polarography for the determination of five different metals following the ashing of the paper chromatograms, and Davies ${ }^{20}$ separated cadmium from copper and determined the former polarographically. Similar methods have also been employed by Bishop and Liebman. 21 Titration methods in which the metal is not removed from the paper has been suggested by Lacourt and Heyndryckx 22 for copper, cobalt, and zinc. Each of these methods, however, suffers from the drawbacks of being tedious and time-consuming. Methodic errors associated with elution procedures cannot be avolded, and if the substance of interest is strongly adsorbed, it may not be possible to achieve a quantitative recovery. On the other hand, it is conceivable that the adsorbent may contain extractable impurities that would further complicate matters. The location of the spots may be difficult to ascertain since chromogenic reagents may not be used. More convenient and more rapid than the methods based upon the elution of spots has been the direct estimation of the metal ions resolved on the chromatograms and chromatoplates. Perhaps the simplest method was that used by 
Beerstecher 23 in which, working with a single cation, he determined the spot area with a grid system and related this to concentration incurring a $10 \%$ error. Lacourt and Heyndryckx ${ }^{24}$ determined copper and cobalt by placing the developed chromatogram between the wall of a usual spectrophotometric cell and a prismatic glass adapter. Concentration was then plotted against optical density in the usual manner. A similar plotting procedure was also used by Bergamini and Versorese 25 who separated eight cations by radial paper chromatography. The variation in photometric intensity of the bands, depending on concentration, was then recorded by a densitometric device. The 1imitations of the densitometric methods have been discussed in detatl in several publications. $26-28$

One of the more sensitive methods for the evaluation of cations resolved on chromatoplates employs radioisotopes. Using radioactive tracers Frierson and Jones 29 studied over ten metals resolved on paper chromatograms. Employing a Gelger counter they located the ions by rapid scanning and then coupled this to an automatic recording counting rate meter for quantitative evaluations. Although amounts as low as $10^{-5}$ micrograms could be detected, the method had several disadvantages: the spots must be separated by at least one centimeter with no talling, large concentrations are required in some cases in order to obtain sufficient activity, some metals do not have 
sufficient half-ilves for the time required for the procedure, and the expense is usually greater than by other methods.

Although the thin-layer chromatographic technique offers many distinct advantages, its analytical utility is restricted by two shortcomings. In the first instance, the difficulty experienced in obtaining reproducible $R_{f}$ values with thin-layers usually makes it necessary to run standards alongside the samples for comparison purposes. secondly, the quantitative removal and extraction of individual spots from plates is a tedious process which in some cases cannot be accomplished without decomposition accurring. Both of these operations would become superfluous if lt were possible to effect the in s1tu identification and determination of chemical species separated on thin plates. The use of spectral reflectance for these purposes was suggested by various studies ${ }^{30-32}$ which demonstrated its utility with respect to paper chromatography, and more recently to thin-1ayer chromatography. 33

Diffuse reflectance spectroscopy was studied over 100 years ago by stokes, 34 but the most general theory is that derlved by Kubelka and Munk in 1931,35 and later expanded by Kubelka. 36 Equations derived by other investigators have proved to be special cases or adaptations of those deduced by Kubelka and Munk, and have been compiled by Judd and Wyszecki 37 and Ingle. 38 As contrasted to regular 
reflection, diffuse reflection from a powder is usually regarded as consisting of two distinct parts. The first of these is the regular or mirror reflection, while the second occurs when impinging radiation is partly absorbed and partly scattered with no deflned angle of emergence. These two types of reflection are largely complimentary and the elimination or minimization of regular reflection is important to the measurement of diffuse reflectance. This may be accomplished by using powders with a small grain size, 39 dilution by a non-absorbing component, 40 or mixing of the sample with an abundance of the reflectance standard. 41

The equation formulated by Kubelka and Munk 35,36 for the diffuse reflectance of an infinitely thick, opaque layer can be written as $F\left(R_{\infty}\right)-\left(1-R_{\infty}\right)^{2} / 2 R_{\infty}=k / s$ where $R_{\infty}$ is the relative diffuse reflectance measured agalnst a standard such as magnestum oxide or barium sulfate, and and $s$ are the molar absorption coefficient and scattering coefficient respectively. Since $R_{\infty}$ is relative to some standard, a linear relationship should exist between $F\left(R_{\infty}\right)$ and the absorption coefficient, $k$, provided s remains constant. This has been shown by Kortum and his coworkers ${ }^{42-44}$ to be valid when working with low concentrations of an absorbed species, and when the grain size of the powders employed is less than one micron in diameter. The latter is in accord with the results obtained by zeitin and Nimoto 45 who observed that the particle size of the 
adsorbent can affect reflectance spectra in that absorption bands tended to broaden as particle size increased. This phenomenon was ascribed by Kortum 43,46 to interference by regular reflection, and he found that such interference was diminished if samples were ground fourteen hours in a ball $\mathrm{mill} .^{39}$ Similar results were obtained if commercial grade thin-layer chromatographic adsorbents, which consist of particles having an average diameter of five microns, were employed. 47

However, the use of reflectance spectroscopy as an analytical technique has been primarily limited to routine commercial comparisons. Comparatively little use has been made of this technique in the identification and determination of purely chemical systems. $39,44,45,48-59$ rreatment of the resultant data from reflectance spectrophotometric measurements also varied. Analagous to transmission studies, winslow and Liebhafsky ${ }^{30}$ plotted extinction or the negative logarithm rersus concentration in an analysis of copper and silver. Other calibration plots have been graphed with reflection density against concentration, 60 logarithm of concentration versus reflectance 61 or per centage reflectance, 32 and $2-10$ garithm reflectance versus the square root of concentration. 62 Another approach utilized by Lieu and Frodyma ${ }^{63}$ plotted percent reflectance against the logarithm of concentration to give not only a calibration curve, but also to manifest the optimum range 
for analysis and the maximum accuracy for the species of interest. A critical evaluation of the application of reflectance measurements to the direct analysis of solid mixtures has established the fact that analytically useful data can be obtained with samples in the powdered form. 64 Pruckner et al. has shown that the reflectance spectra of substances concentrated on particulate adsorbents can be used for their identification, and that spectral reflectance can be employed to determine the concentration of dyes scavenged from solution by the batchwise addition of starch. 66 studies by Frodyma et al. ${ }^{33}$ demonstrated that the components of dye mixtures on thin-layer plates can be determined with a precision of approximately $\pm 5 \%$ by direct examination of the plates. If the reflectance measurements are carried out on spots removed from the plates and packed in an appropriate cell, the degree of precision attained is identical to that afforded by transmittance. Similar procedures have been applied successfully to the analysis of amino acids separated on chromatoplates, 67,68 and more recently to chemical species which absorb in the u1traviolet. 69

Adaptions of the conditions used for paper chromatography could therefore be applied to the resolution of inorganic cations by chromatographic separation on cellulose thin-layers. Solvent systems and chromogenic reagents could be used with little or no modifications. Because 
spectral reflectance has been shown to be useful for the in situ identification and determination of substances resolved on thin-layers, the drawbacks of direct examination or chromatograms such as asymetric spots and variations in paper or layer thickness are surmounted.

The analysis of cations resolved on cellulose chromatoplates may be further improved by a differential technique. This procedure for colorimetric determinations was suggested by Kortum, 70 studied in detail by Hiskey and coworkers, $71-73$ and circumvents two difficulties present in the "ordinary" method of analysis: the measurement of very concentrated and very dilute solutions, and lower precisIon than that attained with classical methods of analysis. Reilley and Crawford 74 have made a complete analysis of the errors that are encountered in differential transmittance measurements at low concentrations. The high reflectance method is a modification of the ordinary method whereby low concentrations may be measured with greater accuracy. In the ordinary method the reading scale is set at zero with the photocell in darkness, and the reflectance of the cellulose substrate is set at 100 and is subtracted instrumentally from the reflectance of the sample. In the high reflectance method, however, the scale is set to read zero with a known concentration of the substance being measured, and is somewhat greater than the unknown sample. The scale is set to 100 in the usual maner. Under these 
modified conditions, the actual reading scale in the high reflectance range is effectively increased. The lowest concentration that can be employed for the setting of the differential standard is determined by the balancing voltage attainable from the zero control. Lermond and Rogers ${ }^{64}$ demonstrated that a differential approach could be used to measure the reflectance of samples of dyed cloth, and suggested that such a procedure could be useful for other chemical systems.

With the promlse of increased precision and sensitivity, the application of the differential approach to the spectral reflectance analysis of inorganic cations should further extend the analytical utility of this technique, especially to a system such as sea water where many metals are present in trace quantities. Although several analytical systems of great sensitivity have been applied to the direct analysis of trace metals in sea water, adequate precision and accuracy for reliable characterization can best be achieved by preconcentration prior to analysis. There are several procedures available for preconcentration of sea water. Removal of the water, either by evaporation or freeze-drying, 75 permits concentration of a sample of ocean water by a factor of about 30 , and therefore will provide a concentrate with many trace elements at levels sufficient for sensitive methods of analysis. One drawback to this technique is that large amounts of 
sodium and chlorine are present in the concentrate. A system of cocrystalization was developed by Weiss and his coworkers ${ }^{76}$ for the determination of silver in sea water using thionalid. This process is distinguished from coprecipitation in that an organic reagent combines with the trace element of interest directly in aqueous solution. No additional carrier is required. Separation from interfering elements collected on the crystals, however, require ashing, redissolution, and separation of the metallic constituents by ion exchange. Also the existence of different chemical species of the elements of interest may reduce the recovery of the total amount in the water. Coprecipitation techniques in which a carrier is added to the sea water has also effectively scavenged trace metals. The most commonly used carrier is ferric hydroxide, and Laevastu and Thompson 77,78 determined nickel and cobalt using the natural collectors present in sea water. Sorption methods have long been used for the removal of substances from dilute solutions by column chromatography. Carritt ${ }^{79}$ proposed a method whereby the sample is passed through a cellulose column Impregnated with dithizone. However, a slow flow rate is frequently necessary for quantitative recovery and large amounts of concentrated acid are required to elute the adsorbed metals. Solvent extraction has also been widely used and with proper cholce of reagents, the extraction may be selective for elther a 
narrow or broad range of elements. Although the methods of solvent extraction are most regularly employed for the isolation of a single substance, multi-element extrac-

tion has been employed to some extent. $80-8$ ? This last method was found to be most-expedient for this research because of its speed, simplieity, and verdatility. The isolation of a substance can be made as complete as desired in most cases by repetition of the extraction. Removal of the extracted solutes from the organic phase for subsequent analysis can be easily and efficientiy accomplished by back-extraction. After preconcentration of the metals from sea water and their isolation from the major constituents, identification and determination of the cations could be carried out be the application of a reflectance spectrophotometric technique to thin-layer chromatography. The high reflectance method outlined above would appear to be suitable for the problem at hand. 


\section{EXPERIMENTAL}

A. The Rapid Identification of Cations Resolved on ThinLayer Plates.

All reagents employed were of analytical grade or comparable purity. The cations-- $\mathrm{Al}^{3+}, \mathrm{Bi}^{3+}, \mathrm{Cd}^{2+}, \mathrm{Cr}^{3+}$, $\mathrm{Co}^{2+}, \mathrm{Cu}^{2+}, \mathrm{Fe}^{3+}, \mathrm{Pb}^{2+}, \mathrm{Mn}^{2+}, \mathrm{Hg}^{2+}, \mathrm{Ni}^{2+}, \mathrm{Ag}^{+}, \mathrm{Sn}^{2+}$, and $\mathrm{zn}^{2+}-$ were employed in the form of aqueous stock solutions. A $1 \mathrm{mg} / \mathrm{ml}$ solution of each cation was prepared by dissolving appropriate amounts of the nitrate salt in distilled water. In the sases of bismuth, mercury, and tin, the solution was also made $3 M$ with respect to nitric acid. These stock solutions were applied as spots by means of a $10 \mu 1$ Hamilton microsyringe.

A Desaga-Brinkmann Model SII applicator was employed to coat the $20 \times 5 \times 0.35 \mathrm{~cm}$ plates with a 17:3 water MN-cellulose powder 300 (Macherey, Nagel and Co.; 516 Dllren, Germany) mixture. The helght of the applicator gate was set at $0.50 \mathrm{~mm}$. After the plates had been dried for $30 \mathrm{~min}$ at $75^{\circ}$ in a mechantcal convection oven, they were developed by the ascending technique with the use of a $1: 3$ $12 \mathrm{~N}$ hydrochlorlc acid - 1-butanol mixture until traces of Iron found to be present in the adsorbent had been displaced to the top of the plate. These pretreated plates were then dried and stored in a desiccator. After spotting the plates were dried with compressed air and developed in one dimension by the ascending 
technique with the use of the hydrochloric acid-1-butanol mixture similar to a procedure devised by Reeves and crumpler. ${ }^{11}$ The developed plates were dried at $75^{\circ}$ for 30 min and then sprayed with a mixture consisting of equal volumes of dithizone $(0.05 \%$ w/v in carbon tetrachloride) and 8-hydroxyquinoline ( $1 \%$ w/v in carbon tetrachloride), which was applied by an atomizer used in conjunction with compressed air. After the plates had been air-dried for $10 \mathrm{~min}$, the spots were excised from the plates, ground in an agate mortar approximately 10 sec, and packed into a windowless reflectance cell. The cell consisted of a $35 x$ 40-mm plastic plate affixed to white paperboard of similar dimensions with two pieces of masking tape. As shown in Figure 1, which presents the dimensions of the cell elements as well as a sketch of the assembled cell, the plastic plate had a circular opening, $16 \mathrm{~mm}$ in diameter, in Its center. The cell was packed by introducing the sample into the opening and then compressing it with a fitted tamp made of an aluminum planchet affixed to a cork stopper. 69

The reflectance spectra of these samples were recorded with the use of a Beckman Model DK-2 Spectrophotometer fitted with a standard reflectance attachment. The reference standard in all cases consisted of approximately $90 \mathrm{mg}$. of adsorbent from the plate under examination. 


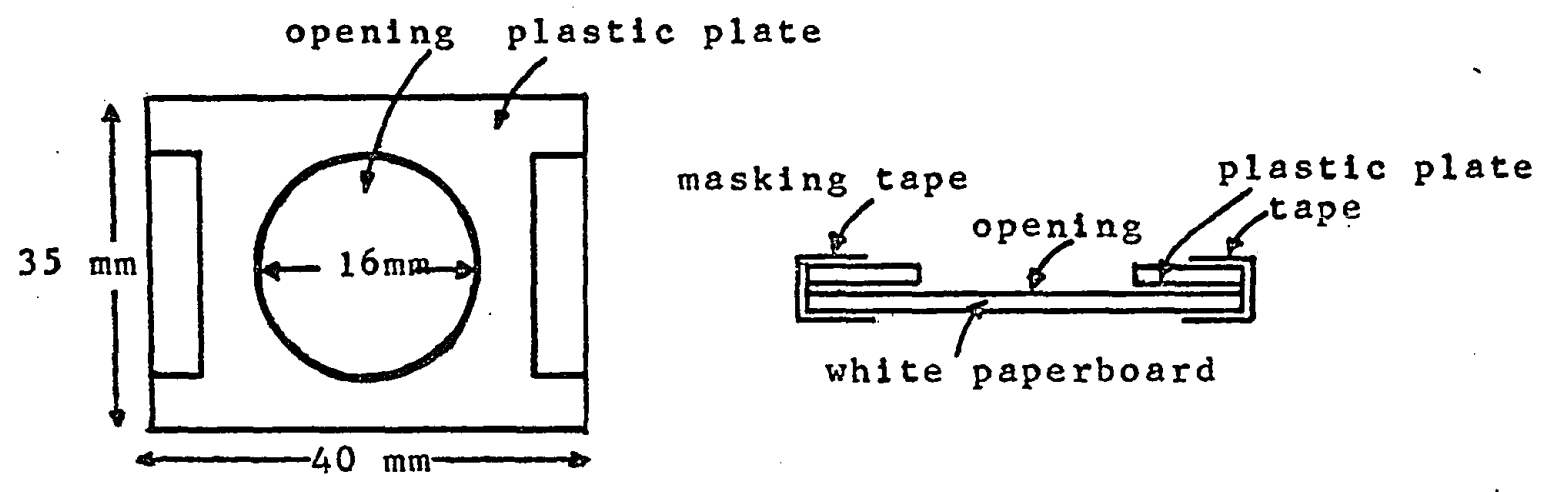

(A)

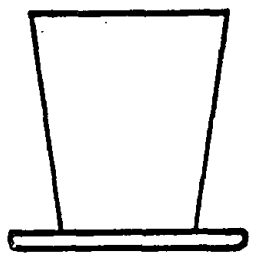

(B)

F1g. 1. (A) Dimensions of cell elements and sketch of assembled windowless ce11. (B) Tamp used to pack cell. 
B. The Determination of Copper, N1ckel, and Zinc.

All reagents were of analytical grade or comparable

purity. Nitrate salts of the cations, $\mathrm{Cu}^{2+}, \mathrm{Ni}^{2+}$, and $\mathrm{Zn}^{2+}$, were used in the form of aqueous stock solutions and contained $3.177 \mathrm{~g} / 1,2.937 \mathrm{~g} / 1$, and $3.269 \mathrm{~g} / 1$ respectively of the metal. These stock solutions were applied as spots by means of a $10 \mu 1$ Hamilton microsyringe.

The $20 \times 20 \times 0.35 \mathrm{~cm}$ plates were prepared as outlined in the previous section, spotted with test solution; dried with compressed alr; and developed as before with the hydrochloric acid - 1-butanol mixture. The developed plates were dried for $30 \mathrm{~min}$ at $75^{\circ}$, sprayed with the appropriate chromogenic reagent or reagents, and again dried for $20 \mathrm{~min}$ at $75^{\circ}$. Spray reagents employed consisted of 1 part of $29 \%$ ammonia to 9 parts of a $1 \%$ solution of dimethylglyoxime in $95 \%$ ethanol for nickel; a 1:2 mixture of $20 \%$ aqueous hydroxylamine hydrochloride and a saturated solution of neocuproine in absolute alcohol for copper; and a 1:5 mixture of a $1 \%$ aqueous solution of potassium ferricyanide and a saturated solution of 3,3'-dimethylnaphthidine in absolute alcohol for zinc. The dimethylglyoxime, neocuproine, and 3,3i-dimethylnaphthidine were obtained from the J. T. Baker Chemical Co., $K$ and K Laboratories, and the CIty Chemical Corp., respectively.

The resolved cations were ldentified by means of their reflectance spectra, which were recorded with the use of a 
Beckman Model DK-2 Spectrophotometer fitted with a standard reflectance attachment. Samples for this purpose were prepared by carefully excising spots from the developed plates and placing them in a windowless reflectance cell atop approximately $40 \mathrm{mg}$ of cellulose removed from the plate under examination. A Beckman Model DU Spectrophotometer, similarly fitted with a reflectance attachment, was employed in the quantitative studies. In these studies, spots were removed from the developed plates along with enough adsorbent to make up an analytical sample weighing $40 \pm 0.1 \mathrm{mg}$. This sample was then ground in a small agate mortar for three sequences of thirty seconds each to insure homogeneity. Between sequences the mixture was loosened from the body of the mortar with a spatula. The sample was then packed in the windowless cell mentioned above and its reflectance at the absorption maximum of the compound in question was measured. Except for the fact that the openIngs were only $16 \mathrm{~mm}$ in diameter, the reflectance cells employed in this study were identical with cells described earlier. 69 In all cases, reference standards consisting of adsorbent from the plate under investigation were prepared In the same manner as the analytical sample.

C. Differential Reflectance Spectroscopy. A high reflectance method.

The solutions of the three metals, copper, nickel, and zinc, employed in this study were prepared as outlined 
In the previous section. The procedures for preparation and measurement of the analytical samples is also the same as described above.

D. The Application of Reflectance Spectroscopy to the Analysis of Some Trace Metal Cations in Sea Water. All reagents were prepared from analytical grade chemlcals or comparable purity. Delonized, distilled water was used throughout the study.

The sea water samples were collected in four-liter plastic bottles from the Koko Head shore, Oahu, and filtered through 0.45 micron Milipore filters (M111ipore Filter Corporation, Bedford, Massachusetts). One liter of water was then transferred to a separatory funnel, and the pH adjusted to approximately 2 with distilied hydrochloric acid. Copper was extracted with at least 3 portions of $0.002 \%(w / v)$ dithizone in carbon tetrachloride and until the green color of the dithizone remalned unchanged. The pH of the water sample was then increased to approximately 8 with ammonia; nickel and zinc were extracted with $0.02 \%$ (w/v) dithizone in carbon tetrachloride until the green dithizone color persisted. The organic extracts vere combined, and the metals back-extracted into the aqueous phase with 6 N hydrochloric acid. The acid solution was transferred to a $25 \mathrm{ml}$ volumetric flask and diluted to the mark with water. An appropriate aliquot of this solution was pipetted into a beaker, $0.2 \mathrm{ml}$ of $70 \%$ perchloric acid 
22

was added, and the solution was taken to dryness. The resIde was dissolved in a few drops of $8 \mathrm{~N}$ hydrochloric acid and applied to the cellulose thin-layer plates by means of a micropipet.

The plates were prepared, pretreated, developed and the analytical samples were readied as described in Experimental Section B. Spectroscopic measurements were made with a Beckman Model DU Spectrophotometer fitted with the standard reflectance attachment. 


\section{RESULTS AND DISCUSSION}

A. The Rapid Identification of Cations Resolved on ThinLayer Plates.

Although Inorganic cations have been chromatographed on the usual inorganic layers, cellulose layers and on ion exchange layers, 7 the use of cellulose has the advantage that many of the techniques which have been developed for paper chromatography ${ }^{8-15}$ can be employed with chromatoplates with 1ittle or no modification. Unfortunately the problem of identifying cations separated on cellulose thin-layers has not been satisfactorily resolved since the $R_{f}$ values obtained with layers are not as reproducible as those obtained with paper. Although the use of chromogenic reagents, such as 8-hydroxyquinoline and hydrogen sulfide, is sometimes helpful, most reagents employed in this manner are not specific enough. To circumvent this difficulty, use is often made of several chromogenic reagents. This device, however, is time-consuming in that a separate thin-layer plate is usualiy required for each reagent, and some of the advantage accruing to the use of cellulose layers rather than paper 18 thus dissipated. When plates spotted with $10 \mathrm{pg}$ of each of the stock solutions of cations were developed according to the procedure outlined in the experimental section, the order of separation of the lons was consistent with that observed with the use of paper. 11 Whenever comparative 
data were avaliable, the $R_{f}$ values, which are listed in Table I, were found in most cases to be similar to those reported for paper chromatography. With the exception of aluminum and chromium, the cations reacted with the dithizone in the chromogenic spray to give highly-colored spots which were easily visible to the naked eye. In the case of the aluminum and chromium, which reacted with the 8-hydroxyquinoline in the spray, the spots became visible when the plates were viewed under ultraviolet light (maximum at $350 \mathrm{m \mu}$ ). When the spots were excised from the plates and prepared for the measurement of reflectance as described, the analytical samples were found to weigh from 80-90 mg. In all cases except aluminum and chromium, the reflectance spectra had well-defined absorption maxima whose locations are listed in Table I. Representative of the reflectance spectra which were obtained for the different cations adsorbed on cellulose after the plates had been sprayed with the dithizone-oxine reagent are the three spectra depicted in Figure 2. Although it was possible by means of such spectra to distinguish among many of the lons, there were several lon-palrs whose spectra vere to simflar as to rule out the possibility of making an unequivocal identification on the basis of spectral data alone.

This situation was resolved by taking advantage of - the fact that the structure of the spectra was pH- 
TABLE I

$R_{f}$ Values and Spectral Data for Cations Adsorbed on MN-Cellulose

After Spraying with Dithizone-oxine Reagent

After Spraying with Followed by Ammonia

\section{Cation}

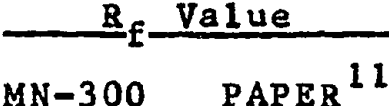

Aluminum Bismuth

Cadmi um

Chromium

Cobalt

Copper

Iron

Lead

Manganese

Mercury

Nicke 1

Silver

Tin

Zine

$\begin{array}{ll}0.04 & 0.04 \\ 0.56 & 0.60 \\ 0.90 & 0.83 \\ 0.07 & -.-5 \\ 0.41 & 0.39 \\ 0.51 & 0.51 \\ 0.93 & 0.92 \\ 0.30 & -.-2 \\ 0.16 & -.-5 \\ 0.88 & 0.86 \\ 0.09 & 0.04 \\ 0.00 & 0.00 \\ 0.80 & -.59 \\ 0.87 & 0.79\end{array}$

Dithizone-0xine Reagent

ABSORPTION SENSITIVITY MAXIMUM (mp) ( $\mathrm{mg}$ )

505
498
-512
502
380
498
510
492
503
492
510
513

$2 \cdot 2$

1.6

0.5

0.6

2.7

0.5

2.2

0.5

1.2

2.0

0.9

0.7
Treatment

ABSORPTION SENSITIVITY
MAXIMUM (m $\mu) \quad(\mu g)$

380

515

519

414

564

398

597

556

507

514

574

526
2.3

2.2

1.6

6.5

0.5

0.6

0.9

2.2

2.6

0.6

0.6

0.7 


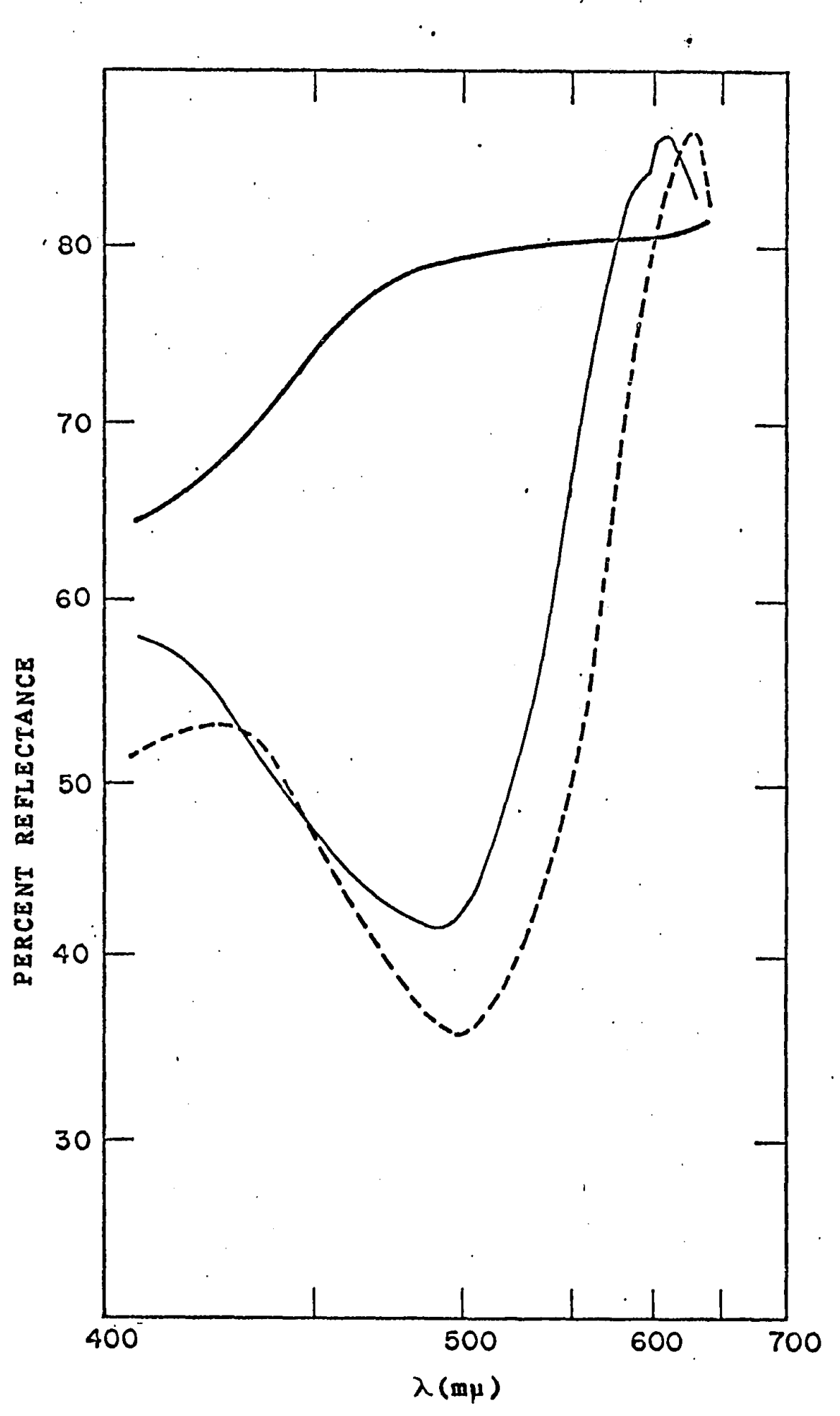

F1g. 2. Reflectance spectra obtained for $10 \mu g$ of chromium (- lead $(--)$, and silver (-) cations adsorbed on cellulose after chromatoplates had been sprayed with dithizone-oxine reagent. 
dependent. After the first set of spectra had been obtained, the reference and sample cells were exposed to ammonia fumes for at least two minutes in a chamber containing $15 \mathrm{M}$ ammonia, and a second set of reflectance spectra were recorded. Except for the ones obtained for mercury and tin, these spectra, which were always recorded directly after the reflectance cells had been removed from the ammonia chamber, also exhlbited well-defined absorption maxima. The three spectra shown in Figure 3 are characteristic of the reflectance spectra which constituted the second set. Since these are spectra obtained for the same three cations whose spectra are also presented In Figure 2, a comparison of the two figures will give some indication of the spectral changes that were induced by the ammonia treatment. The wavelengths at which absorption maxima occurred in the spectra that were obtalned for the various cations following this treatment are 1 isted in Table I. By making use of the data provided by both sets of reflectance spectra, it should be possible to identify all fourteen of the cations following their resolution on chromatoplates without too much difficulty. Even in the case of the bismuthmickel cation-pair, which provides the least satisfactory set of spectral data for this purpose, the relative rates of migration of the two spots are so disparate that there is little likelihood of mistaking one cation for the other. 


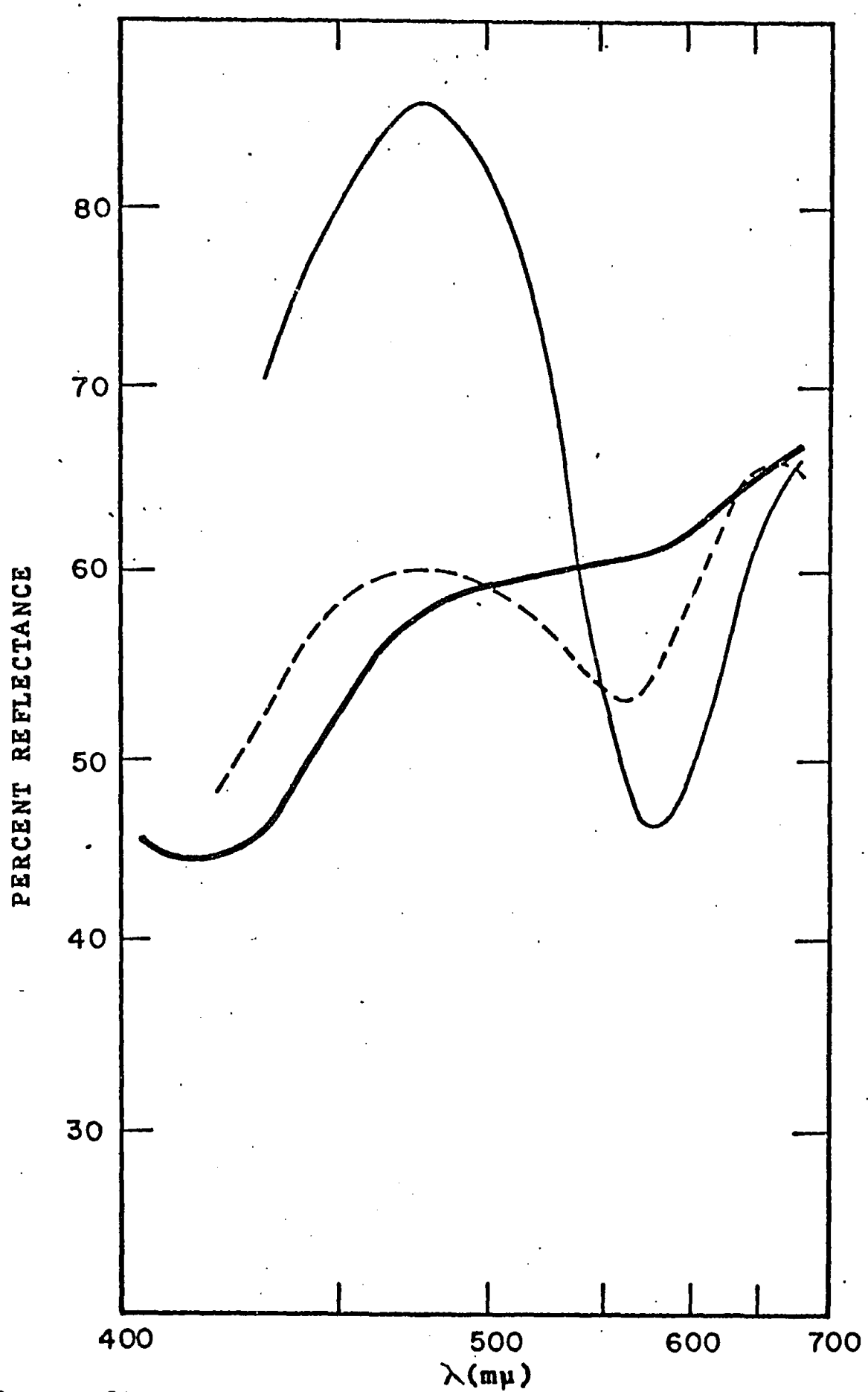

F1g. 3. Reflectance spectra obtained for $10 \mu g$ of chromium (-), lead (--) and silver (-) cations adsorbed on cellulose after chromatoplates had been sprayed with dithizone-oxine reagent and subsequently exposed to ammonia fumes. 
The sensitivities provided by this approach, which are also listed in Table I, were found to vary from 6.5 to $0.5 \mu 8$. A two- to four-fold increase in sensitivity was usually achieved if the analytical sample were prepared by centering the excised spot atop a uniformly-thick leger of $90 \mathrm{mg}$ of adsorbent from the plate undergoing examination which had been packed in the reflectance cell beforehand with the use of the tamp. In a few cases where the color of the complex was especially intense, as with mercury, the increase was as much as ten-fold.

It was possible to Identify the cations in some mixtures even more readily by recording the reflectance spectra without removing the spots from the chromatoplates. This involved positioning the plates at the sample exit port of the reflectance attachment so that each spot was centered, in turn, in the impinging beam of 1 ight. The reference beam was directed at adsorbent on a second plate which had been treated in the same manner as the one under examination. In practice this is usually a plate on which another mixture of cations is being resolved. White paperboard was inserted behind both pletes to serve as a reflecting background during the recording process. Although more rapid, this approach is effective only with thin-layer plates on which the spots are relatively well dispersed. Furthermore, spectra obtalned in this manner, although still useful, tend to be less satisfactory for 
purposes of Identification than those obtained with the use of reflectance cells. This is shown in Figure 4, which contrasts spectra obtained by direct measurement with spectra obtained for the same cations by means of the procedure outlined in the experimental section. Finaliy, if It is also Intended to make quantitative use of the spectra the precision of reflectance measurements carried out on spots removed from the plates and packed in a cell is significantly greater than that provided by direct measurements. 33

B. The Determination of Copper, Nickel, and Zinc. Although reflectance spectroscopy has found some inorganic and physical applications, $44,50,51$ surprisingly little use has been made of the technique in the analysis of cations resolved by chromatographic procedures. Rel1able methods have been devised for the determination by means of spectral reflectance of species resolved on thinlayer plates. 67-69 As with paper, quantitative techniques involve either a direct examination of the separated components, such as a comparison of the sizes of spots, or an elution of the resolved species from the substrate followed by the analysis of the eluant by some conventional means. Recently, Ryan and Frei ${ }^{84}$ employed the spectral reflectance technique to determine cobalt, nickel, and copper following their separation on chromatoplates. Because the 


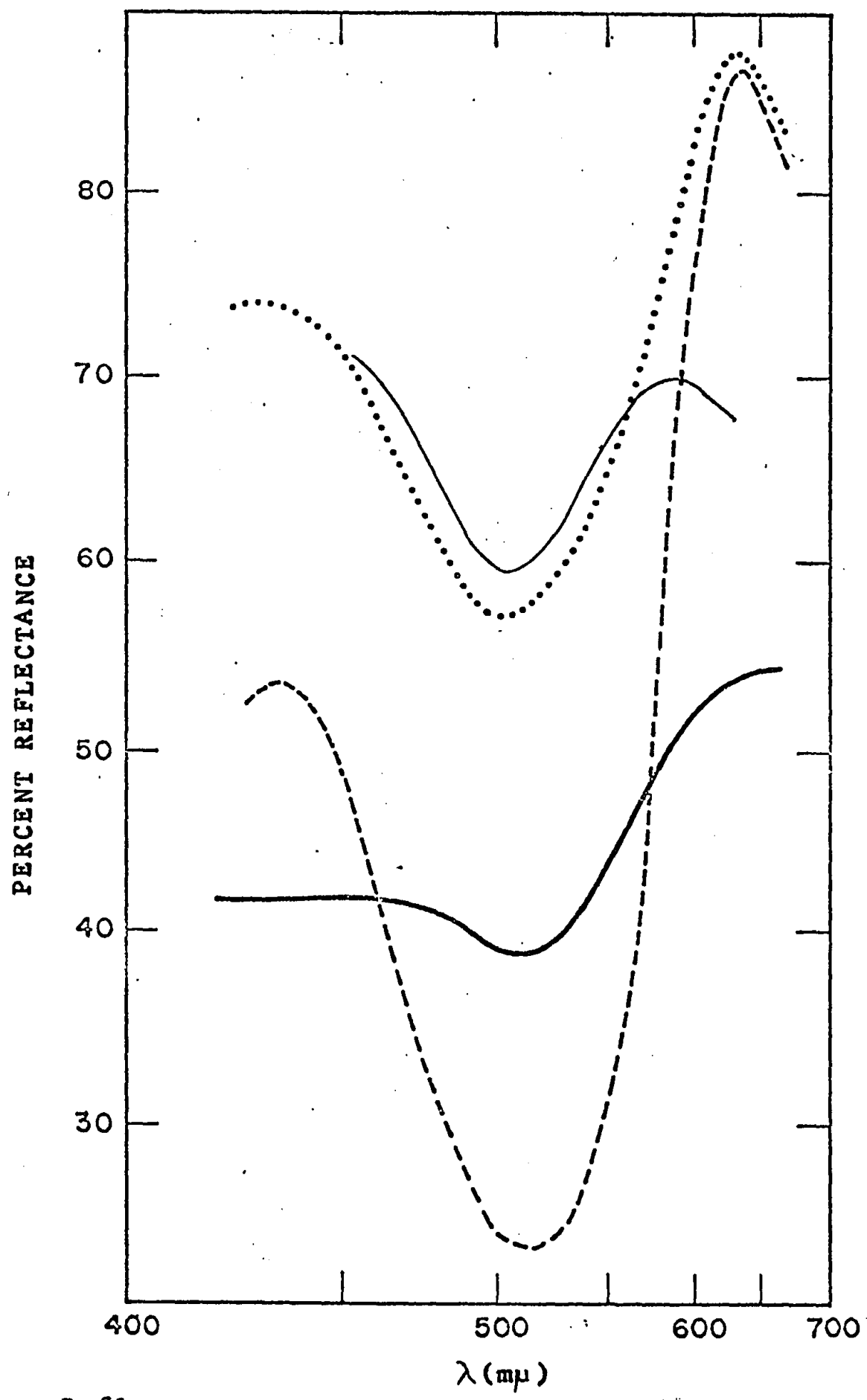

Fig. 4. Reflectance spectra of $5 \mu 8$ of cobalt and unc cations adsorbed on cellulose after thin-layer plates had been sprayed fith dithizone-oxine reagent. Cobalt ( ) and zinc (-) spectra obtained by direct measurement contrasted with cobalt (․) and 21 inc $(-\infty)$ spectra with the use of reflectance cells. 
rubeanic acid employed as the chromogentc reagent is nonspecific, however, use of this procedure is limited to systems where the opportunities for interference are minimal .

This difficulty can be avolded by a judiclous selection of chromogenic reagents such that only the ion under Investigation will react to form a colored product with a particular reagent. Hence, a procedure was developed for the determination of copper, nickel, and zinc, three lons which play an important role in various processes occurring in blological systems and natural waters.

Excellent resolution was achieved with the use of the chromatographic procedure outlined in the experimental section, with $R_{f}$ values of $0.09,0.51$, and 0.87 being obtained for the nickel, copper, and zinc cations, respective1y.

The chromogenic reagents employed were selected on the basis of the stability of the color generated by their application, their sensitvity, and their specificity for the cation in question. All three formed colored products which underwent no change with time when stored over calcium chloride out of direct 11ght. Two of them, dimethylglyoxime for $n i c k e 1^{85}$ and neocuproine for copper, $^{86,87}$ have found wide analytical application because of their sensitivity. The zinc analysis was achieved by means of a modified turbidimetrlc procedure 88 which 
depends upon the oxidation of $3,3^{\prime}$-dimethylnaphthidine by potassium ferricyanide to give a blue-violet colored p-quinoldal difmine. 89 The intensity of the color of this product, which is adsorbed on the insoluble zinc ferrocyanide, is such that it has been used as the basis for a method designed to detect microquantities of zinc. 90 In any event, the use of these three chromogenic reagents in this research not only made it possible to detect amounts of nickel, copper, and zinc as low as $0.014,0.023$, and $0.029 \mu \mathrm{g}$, respectively, but also resulted in the formation of adsorbed colored products whose reflectance spectra were unique enough to permit their ready identification. The spectra obtained, which are depicted in Figure 5, had absorption maxima at $448 \mathrm{~m} \mu$ for copper, $540 \mathrm{~m} \mu$ for nickel, and $565 \mathrm{mp}$ for zinc. The spectrum of the nickel-dimethylglyoxime complex adsorbed on the cellulose powder was identical vith that obtained by Vaeck ${ }^{31}$ for the complex adsorbed on paper.

When the three chromogenle reagents were tested for selectivity, the results obtained, which are presented in Table II, pointed up the advantages afforded by the use of a specific rather than a non-specific reagent in the analysis of cations resolved on thin-lager plates. Since only copper of the fourteen cations tested gave a color reaction with neocuproine, use of this particular reagent involved no special precautions to avold interferences. 


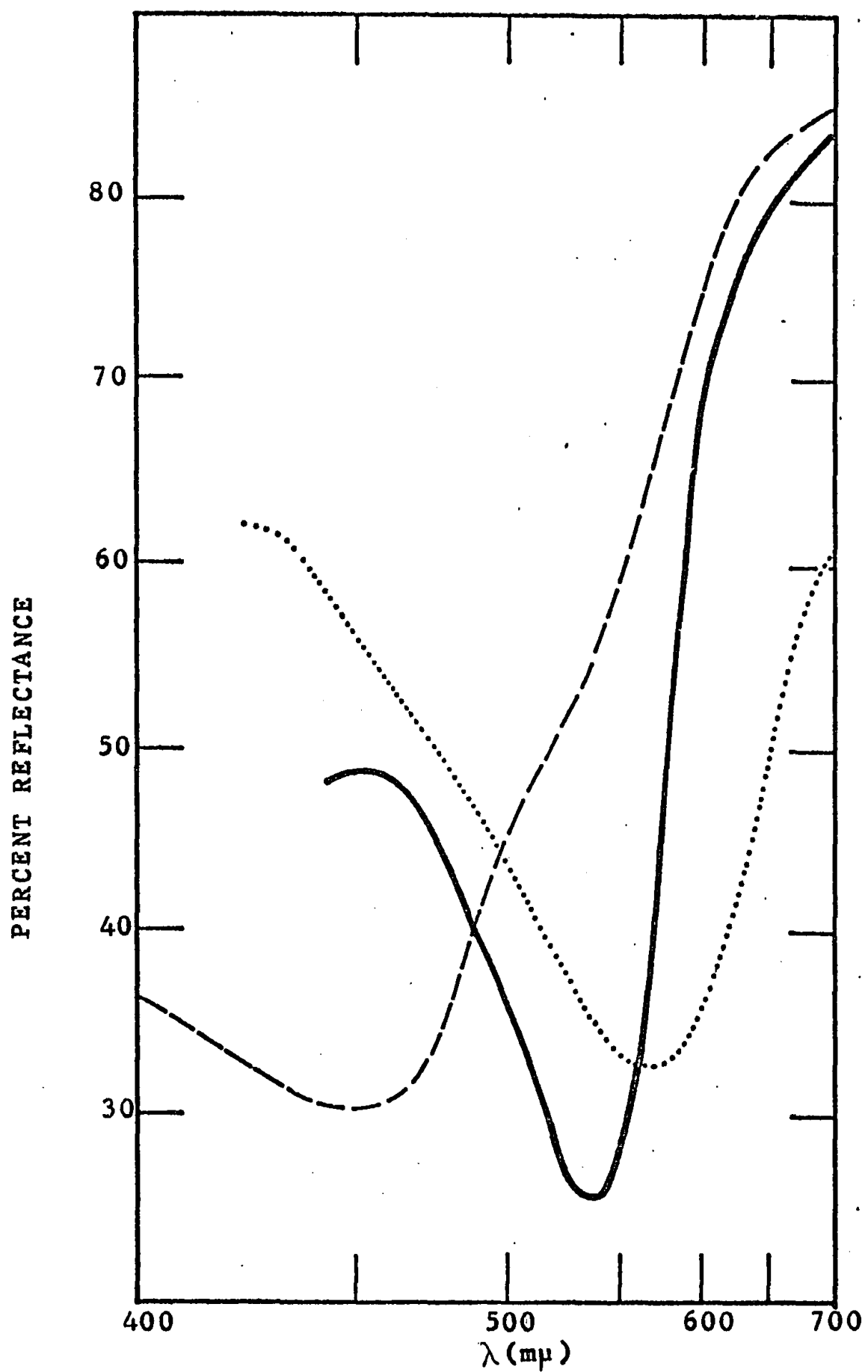

Fig. 5. Reflectance spectra obtained for $0.1 \mu g-a t$ of coppar (--), nickel (-) and zinc ( $\cdots)$ cations adsorbed on cellulose and sprayed with the appropriate chromogenic reagent. 
TABLE II

$R_{f}$ Values and Color Reactions Obtained for Cations Adsorbed on MN-Cellulose $R_{f}$

Cation Value

Color Reactions

\begin{tabular}{|c|c|c|c|c|}
\hline \multirow[t]{2}{*}{ tion } & \multirow[t]{2}{*}{ Value } & \multicolumn{3}{|c|}{ Color Reactions } \\
\hline & & Neocuproine & Dimethylgl yoxime & $3,3^{\prime}-$ Dimethyl naphthidine \\
\hline $\begin{array}{l}\text { Silver } \\
\text { Aluminum } \\
\text { Chromium } \\
\text { Nickel } \\
\text { Manganese } \\
\text { Lead } \\
\text { Cobalt } \\
\text { Copper } \\
\text { Bismuth } \\
\text { Tin } \\
\text { Zinc } \\
\text { Mercury } \\
\text { Cadmium } \\
\text { Iron }\end{array}$ & $\begin{array}{l}0.00 ! \\
0.04 \\
0.07 \\
0.09 \\
0.16 \\
0.30 \\
0.41 \\
0.51 \\
0.56 \\
0.80 \\
0.87 \\
0.88 \\
0.90 \\
0.93\end{array}$ & $\begin{array}{l}\text { none } \\
\text { none } \\
\text { none } \\
\text { none } \\
\text { none } \\
\text { none } \\
\text { none } \\
\text { yellow } \\
\text { none } \\
\text { none } \\
\text { none } \\
\text { none } \\
\text { none } \\
\text { none }\end{array}$ & $\begin{array}{l}\text { none } \\
\text { none } \\
\text { none } \\
\text { red } \\
\text { none } \\
\text { none } \\
\text { brown } \\
\text { brown } \\
\text { none } \\
\text { none } \\
\text { none } \\
\text { none } \\
\text { none } \\
\text { none }\end{array}$ & $\begin{array}{l}\text { none } \\
\text { none } \\
\text { none } \\
\text { purple } \\
\text { violet } \\
\text { violet } \\
\text { violet } \\
\text { violet } \\
\text { violet } \\
\text { violet } \\
\text { purple } \\
\text { purple } \\
\text { violet } \\
\text { violet }\end{array}$ \\
\hline
\end{tabular}


Dimethylglyoxime was almost as selective, forming a colored product oniy with cobalt and copper in addition to nickel. The migration rates of the cobalt and copper spots relative to the nickel spot are such, however, that not only does neither reaction represent a possibility of interference but both reactions can be prevented from taking place by the simple expedient of masking the chromatoplate appropriately while the chromogenic reagent is being applied. The 3,3'-dimethylnaphthidine, on the other hand, though the most suitable substance found for the zinc analysis, was the least selective of the three chromogenic reagents. Not only were colored products obtained with ten other cations in addition to zinc, but the $R_{f}$ values obtained for tin, cadmium, mercury, and iron were such as to preclude the determination of zinc in mixtures containing any of these three cations. An even less desirable sttuation obtains when a less selective reagent such as rubeanic acid or dithizone is employed. Dithizone, for example, reacts to glve a colored product with twelve of the cations listed in Table II. As a result, because of the overlapping that is experienced when zelatively large amounts of the various cations are chromatographed, it is usualiy not only not possible with the use of dithizone to determine zinc in the presence of tin, cadmium, mercury, and iron, but it is also not possible to determine copper in the presence of lead and bismuth, and 
nickel in the presence of silver and manganese. Another disadvantage that accrues to the use of dithizone as a chromogenic reagent is the decreased sensitsvity that results from the color that it imparts to the adsorbent which is subsequently employed as a standard in the measurement of the reflectance of the analytical sample. 3,3'-Dimethylnaphthidine does not suffer from this drawback.

Although the above discussion pertains to resolutions achieved on cellulose plates, it is possible to achieve similar results for the same cations separated on silica gel and alumina plates by modifying existing chromatographic procedures 3,84 appropriately. For example, using neocuprolne as the chromogentc reagent and alumina plates, one can determine copper in the presence of the other thirteen cations 11 sted in Table II without encountering ang difficulties. If the non-specific dithizone is substituted for the neocuproine, however, it is not possible to determine copper in the presence of cobalt, mercury, and zinc.

Once a procedure had been arrived at for the location and identification of copper, nickel, and zinc cations following their resolution on cellulose thin-1ayer plates, an effort was made to devise a method for thelr determination by the application of spectral reflectance. Calibration plots for the cations adsorbed on cellulose 
were prepared by applying different concentrations of each cation as spots to thin-layer plates, which were then developed, dried and readied for the measurement of reflectance according to the procedure outlined in the experimental section. When the percent reflectance at the absorption maxima for the different cations adsorbed on MN-cellulose was graphed as a function of the concentrations, the plots obtalned for all three cations were the smooth curves usually encountered in reflectance work. Three such dilution series were run for copper, and four for nickel and zinc, at different times during this research. The average standard deviation observed in the readings obtained for any given concentration of any of the cations amounted to 0.23 reflectance unit. Since this approximates the maximum prectsion provided by the application of spectral reflectance to thin-layer chromatography, 68 the preparation of a new calibration curve for each set of determinations appears to be unnecessary. When the quantitative data are cast in the form percent reflectance versus the logarithm of concentration, as Is done in Figure 6 , the optimum concentration range for maximum accuracy, which corresponds to the straight-ine portion of the curve where the slope is greatest, is emphasized. By employing this slope in conjunction with the error expression, \% Error $=2.303 \mathrm{~d}(10 \mathrm{~g}) / \mathrm{dR}$, it is also possible to estimate the percent error in the 


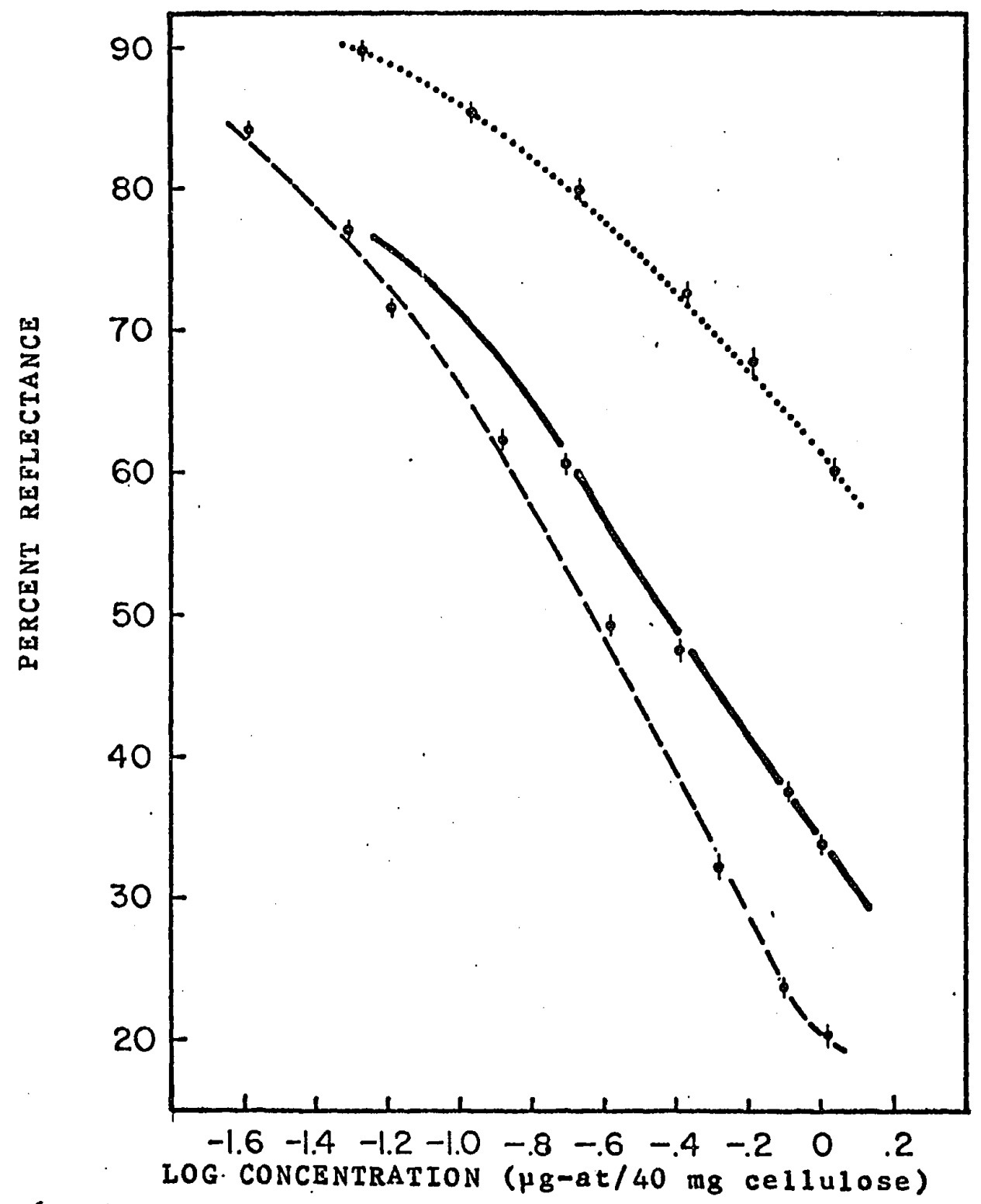

Fi 8. 6. Percent reflectance at the absorption maxima of of the colored products of copper (--), nickel ( $\longrightarrow$ ) and zinc (-.) as a function of the logarithm of the concentration of the cation. 
analysis that would derive from an error amounting to $1 \%$ R. 63 The optimum range and the probable percent error that were deduced in this manner for the analysis of copper, nickel, and zinc adsorbed on cellulose are 1isted in Table III.

The precision that can be attained when the above procedure is employed in the determination of copper, nickel, and zinc was arxived at by running through the analysis with five replicate samples of each cation. As may be seen in Table IV, which summarizes the results of this study, the reflectance reading obtained for optimal concentrations of the various cations adsorbed on celiulose were found to have standard deviations ranglng from 0.30 to 0.70 reflectance unit. If these data are used in conjunction with the analysis error data included in Table III, deviations of this order are found to correspond to deviations of $2.1,2.8$, and 5.6 in the determination of nickel, copper, and zinc, respectively.

C. Differential Reflectance Spectroscopy. A high reflectance method.

Analagous to transmission spectroscopy, the ordinary procedure for spectral reflectance methods for analysis leaves much to be desired with respect to precision when operating near either end of the reflectance scale, i.e., samples of etther very low or very high reflectance values 


\section{TABLE III}

\section{Optimum Range and Probable Error in the Determination of}

Cations Adsorbed on MN-Cellulose

\begin{tabular}{|c|c|c|c|c|}
\hline Cation & $\begin{array}{c}\text { Optimum } \\
\text { Refiectance } \\
\text { Range (\%R) } \\
\end{array}$ & $\begin{array}{c}\text { Optimum } \\
\text { Concentration } \\
\text { Range } \\
\text { ( } \mathrm{g} / 40 \mathrm{mg} \text { adsorbent) } \\
\end{array}$ & $\begin{array}{l}\text { \% Analysis } \\
\text { Error of } \\
\end{array}$ & $\begin{array}{l}\text { Error } / \\
1 \% \mathrm{R} \\
\end{array}$ \\
\hline Copper & $30-75$ & $3.2-39.0$ & -5 & \\
\hline N1 cke 1 & $30-70$ & $4.9-58.7$ & -7 & \\
\hline Zine & $60-80$ & $14.0-75.2$ & -8 & \\
\hline
\end{tabular}


TABLE IV

Reproduciblity of \% Reflectance obtained for Replicate Samples of Cations Adsorbed on MN-Cellulose

\begin{tabular}{lccc} 
Cation & Concentration $(\mu g)$ & Mean Value (\%R) & Standard Deplation \\
\cline { 2 - 4 } & 16 & 48.4 & \pm 0.56 \\
Nickel & 7 & 65.3 & \pm 0.30 \\
Zinc & 26 & 72.6 & \pm 0.70
\end{tabular}


relative to the non- or low-absorbing standard. 63 This limitation in transision spectroscopy may often be eircumvented by adding a differential approach to the spectroscopic measurement and the precision of measurement may be materially improved. 71,74 In view of this, it was decided to develop a new reflectance spectroscopic procedure whereby it would be possible to determine very small quantities of material which thus far cannot be achleved in reflectance spectroscopy. Such a method should also enable the analysis to be carried out with a significant reduction in the error of analysis.

As in transmission spectroscopy, it is justified to assume that a reflectance reading is a linear function of the light reflected from a sample. The relationship between the reflectance reading $R$ and the intensity of the light I reflected from the sample can be expressed as

$$
R=a I+b
$$

where a and $b$ are constants。 Letting $R=1$ when $I=I_{1}$ and $R=0$ when $I=I_{2}$, substitution of the above "boundary" conditions in equation (1) permits a and b to be expressed in terms of $I_{1}$ and $I_{2}$.

$$
\begin{aligned}
& a=1 /\left(I_{1}-I_{2}\right) \\
& b=-I_{2} /\left(I_{1}-I_{2}\right)
\end{aligned}
$$

An expression of the reflectance reading $R$ in terms of light intensities can be obtalned by substituting equations 
(2) and (3) into equation (1).

$$
R=\frac{I-I_{2}}{I_{1}-I_{2}}
$$

In the ordinary method, the zero adjustment is made with the photocell in darkness, 1.e., $R=0$ when $I_{2}=0$; and the scale is set to read 100 with a non- or low-absorbing reference standard exposed to the leam of light, or $R=1$ when $I_{1}=I_{0}$ Letting $I=I_{x}$ and substituting, equation (4) reduces to the familiax expression relating the reflectance reading to 1 ight intensities in the ordinary method.

$$
R=I_{x} / I_{0}
$$

In the high reflectance method developed in this study the scale is adjusted to read zero with a differential standard of higher concentration than that of the sample under investigation with the standard exposed to the beam of 1 ight, $1 . e ., I_{2}-I_{s}$ when $R=0$, and set to read 100 in the same manner as that of the ordinary method, $1 . e, I_{1}=$ $I_{0}$ when $R=1$. Letting $I=I_{x}, R=R_{h}$ and substituting, equation (4) becomes

$$
R_{h}=\frac{I_{x}-I_{s}}{I_{0}-I_{s}}
$$

where $R_{h}$ denotes the reflectance reading obtained with the high reflectance method of measurement. The physical significance of equation (6) is that the reflectance reading 
obtained with the $h i g h$ reflectance method is the ratio of the difference of the intensities of 11 ght reflected from the sample and the differential standard to that of the Intensities of 11 ght reflected from a non- or low-absorbIng standard and differential standard.

The most general theory of diffuse reflectance and the transmission of light-scattering layers was developed by Kubelka and Munk. 35,36 In the case vhere the material under investigation is diluted with a non- or low-absorbing powder and its reflected 11 ght is measured agalnst the pure powder, the equation derived by Kubelka and Munk can be witten in the form 63

$$
c=\frac{k \cdot\left(1-R_{x 0}\right)^{2}}{2 R_{x 0}}
$$

where $c$ is the molar concentration, $R_{x o}$ is the reflectance reading of the sample relative to a non- or low-absorbing standard, and $k$ is a constant. Equation (7) is the Kubelka-Munk $(K-M)$ equation for the ordinary method of analysis.

A similar equation relating concentration and reflectance reading can be deduced for the high reflectance method. By dividing both the denominator and numerator of equation ( 6 ) by $I_{0}$, it can be written in the form

$$
R_{h}=\frac{R_{x o}-R_{s o}}{1-R_{s 0}}
$$


or

$$
R_{x 0}=R_{h}(1-p)+p
$$

since $R_{x o}$ and $R_{\text {so }}$ by definition are the reflectance readings of the sample and the differential standard obtained by the ordinary method of measurement and are therefore equal to $I_{x} / I_{0}$ and $I_{s} / I_{0}$ respectively. In equation (8), $R_{\text {so }}$ is replaced by the constant p since the same differential standard is used for the preparation of the calibration curve and in the reflectance measurement of the unknown sample in an analysis. By combining equations (7) and ( 8 ), the desired $K-M$ equation for a high reflectance method is derived

$$
c=\frac{k}{2} \frac{\left[(1-p)\left(1-R_{h}\right)\right]^{2}}{R_{h}(1-p)+p}
$$

In the special case where $R_{-0}=1 . e$, the differential standard is of such high concentration that the incoming Iight is completely absorbed, this is equivalent to making the zero adjustment with the photocell in darkness in the ordinary method of measurement. Consequently the $K-M$ equation for the high reflectance method is reduced to equation (7) which is the equation for the ordinary method of analysis. It can be seen from equation (9) that in the high reflectance method, a linear relationship exists between $\left[(1-p)\left(1-R_{n}\right)\right]^{2} /\left(R_{h}(1-p)+p\right)$ and concentration, and that the linear plots obtained with the various 
differential standards should have identical slopes and thus can be superimposed on one another, provided the system employed exhibits no deyiation from the $K-M$ equation for the ordinary method. To illustrate this, three systems were selected as mode1s. These were colored compounds of copper, nickel, and zinc as described in the previous section, and all showed strong absorption in the visible region of the spectrum (see Figure 5). These compounds were adsorbed on the cellulose powder commonly used for chromatographic analysis. The experimental data obtalined with these three systems employing varying concentrations of the respective compounds as differential standards are presented in Figures 7 to 9 . When these data are plotted in the form $\left[(1-p)\left(1-R_{h}\right)\right]^{2} /\left(R_{h}(1-p)+p\right)$ versus c, curves in Figures 10 through 12 result. The curves in Figures 10 - 12 are identical to plots with the K-M equation for the ordinary method since equation (9), when $p=0$, is reduced to equation (7). The nickel plot obtained with the photoceli in darkness takes the form of a straight line with the exception of the high concentration region indicating the close conformity of this system to the K-M equation. As predicted by equation (9), the $K-M$ plots for the high reflectance method of the nickel complex also take the form of straight lines and are superimposed on one another. In contrast, the plots for copper and zinc obtalned with the photocell in darkness depart 


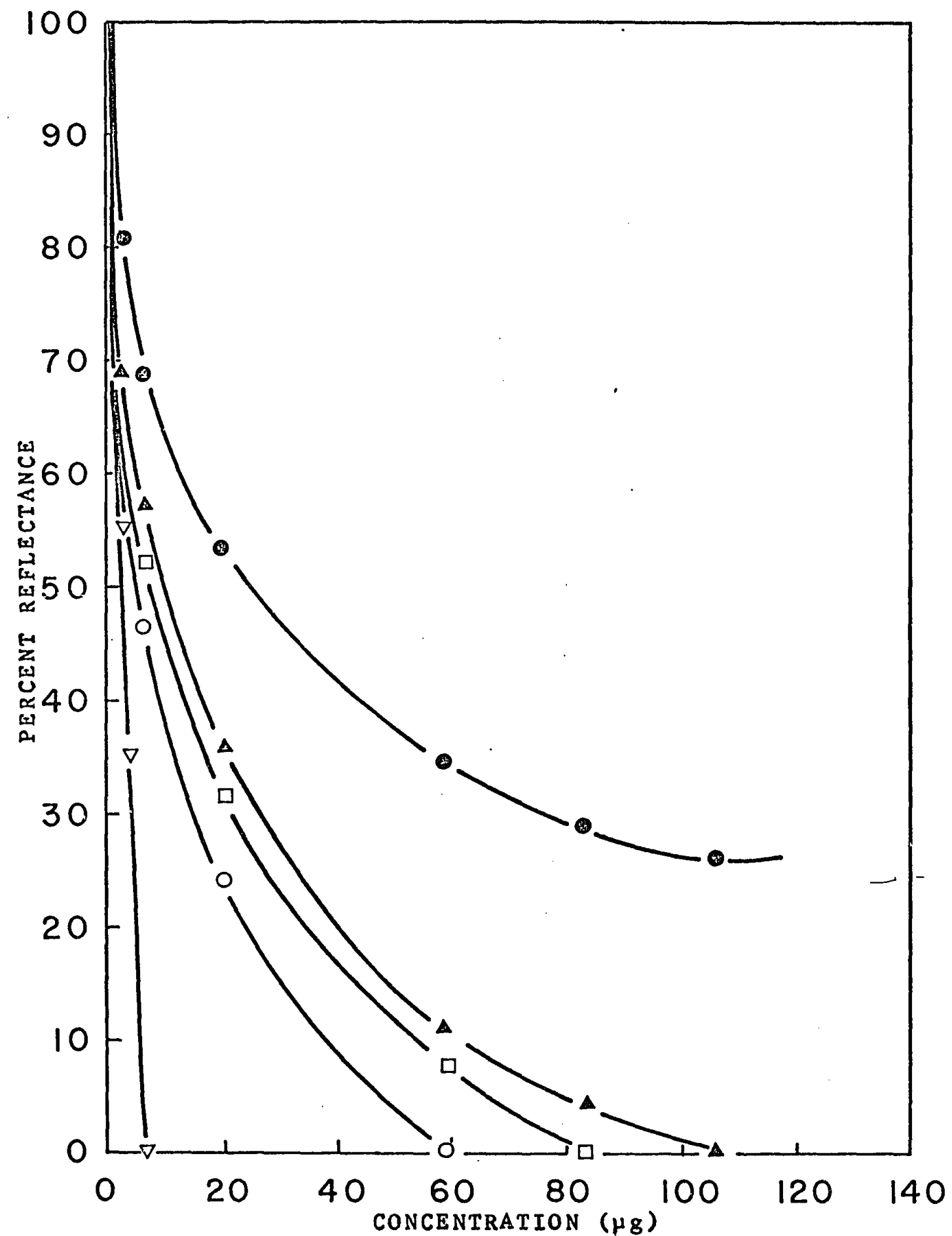

Fig. 7. Percent reflectance at $540 \mathrm{mp}$ of nickel-dimethy1glyoxime adsorbed on cellulose as a function of concentration. Differential standard concentrations ( $\mu \mathrm{g} \mathrm{Ni} / 40 \mathrm{mg}$ cellulose): photocell in darkness (-), 106.7 ( $), 83.0$ $(-\square), 59.3(--), 5.9(-\nabla)$. 


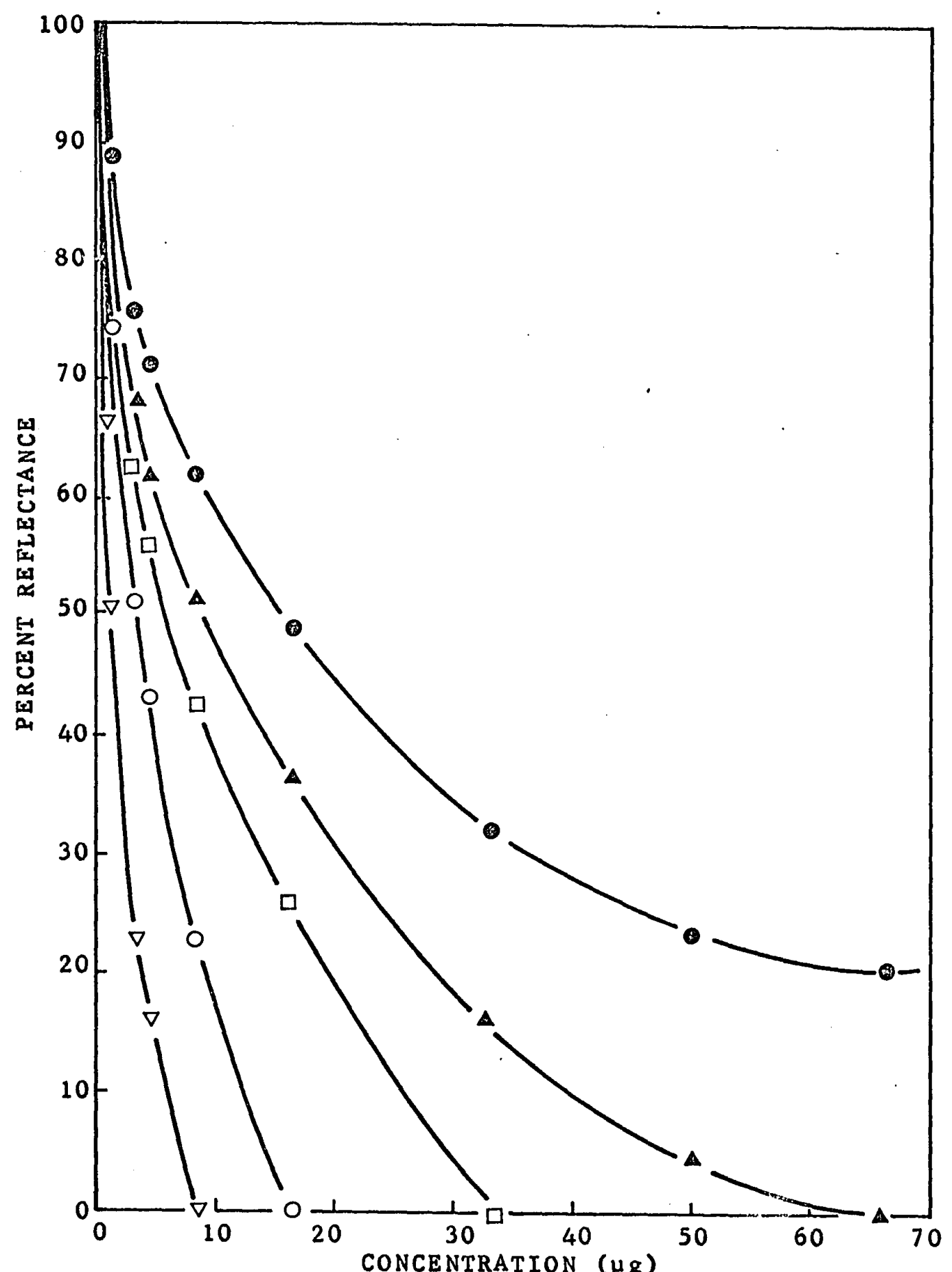

Fig. 8. Percent reflectance at $448 \mathrm{mp}$ of copper-neocuproine adsorbed on cellulose as a function of concentration. Differential standard concentration $(\mu \mathrm{g} \mathrm{Cu} / 40$ mg cellulose): photocell in darkness (- ), 66.8 (- ), $33.4(-1-), 16.7(-0), 8.4(-7)$ ). 


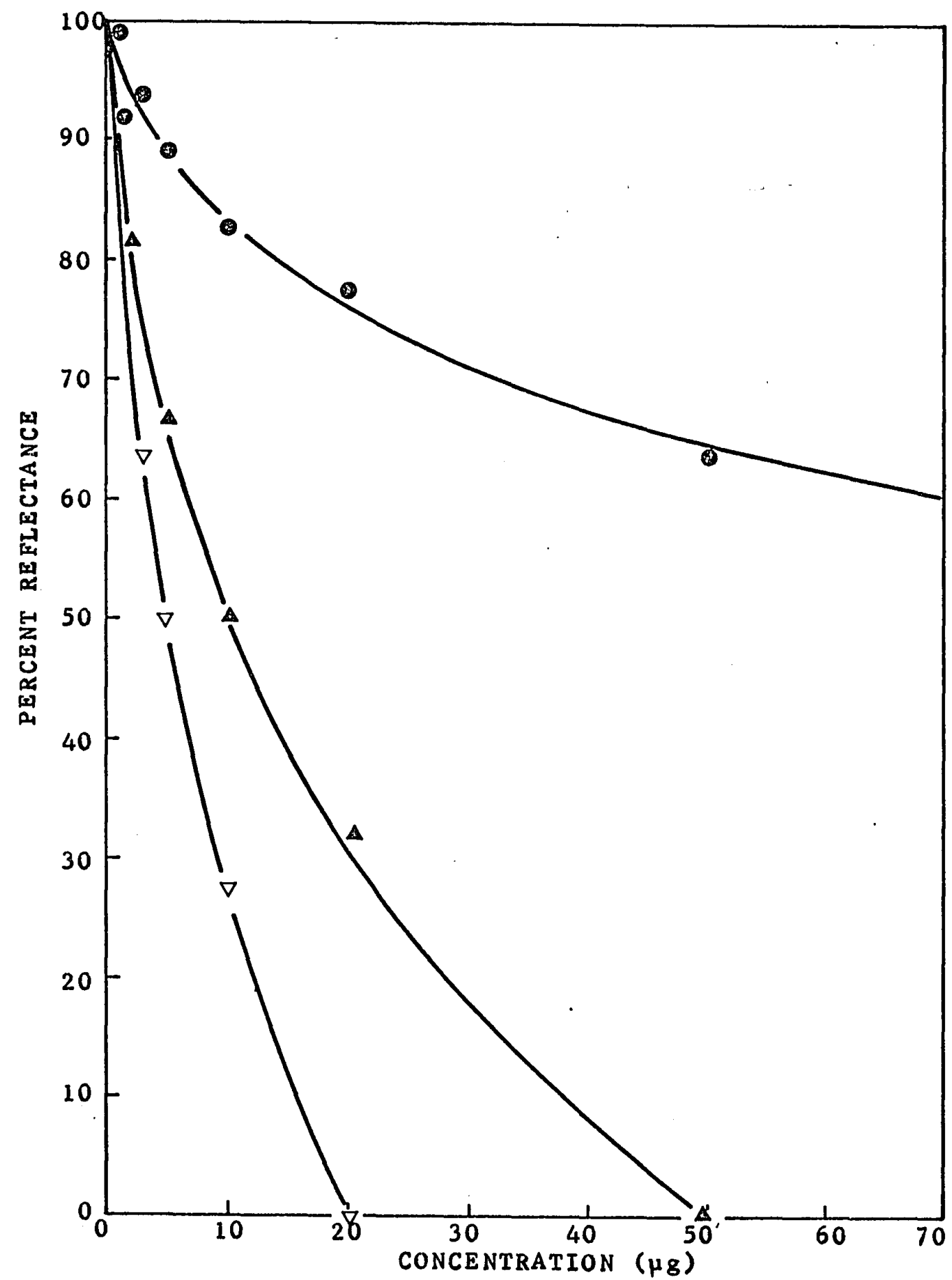

Fig. 9. Percent reflectance at $565 \mathrm{mp}$ of zinc-naphthidine adsorbed on cellulose as a function of concentration. Differential standard concentrations ( $\mu \mathrm{g} \mathrm{zn} / 40$ mg cellulose): photocell in darkness (-), 50 ( At), $20\left(-\nabla_{i}\right)$. 


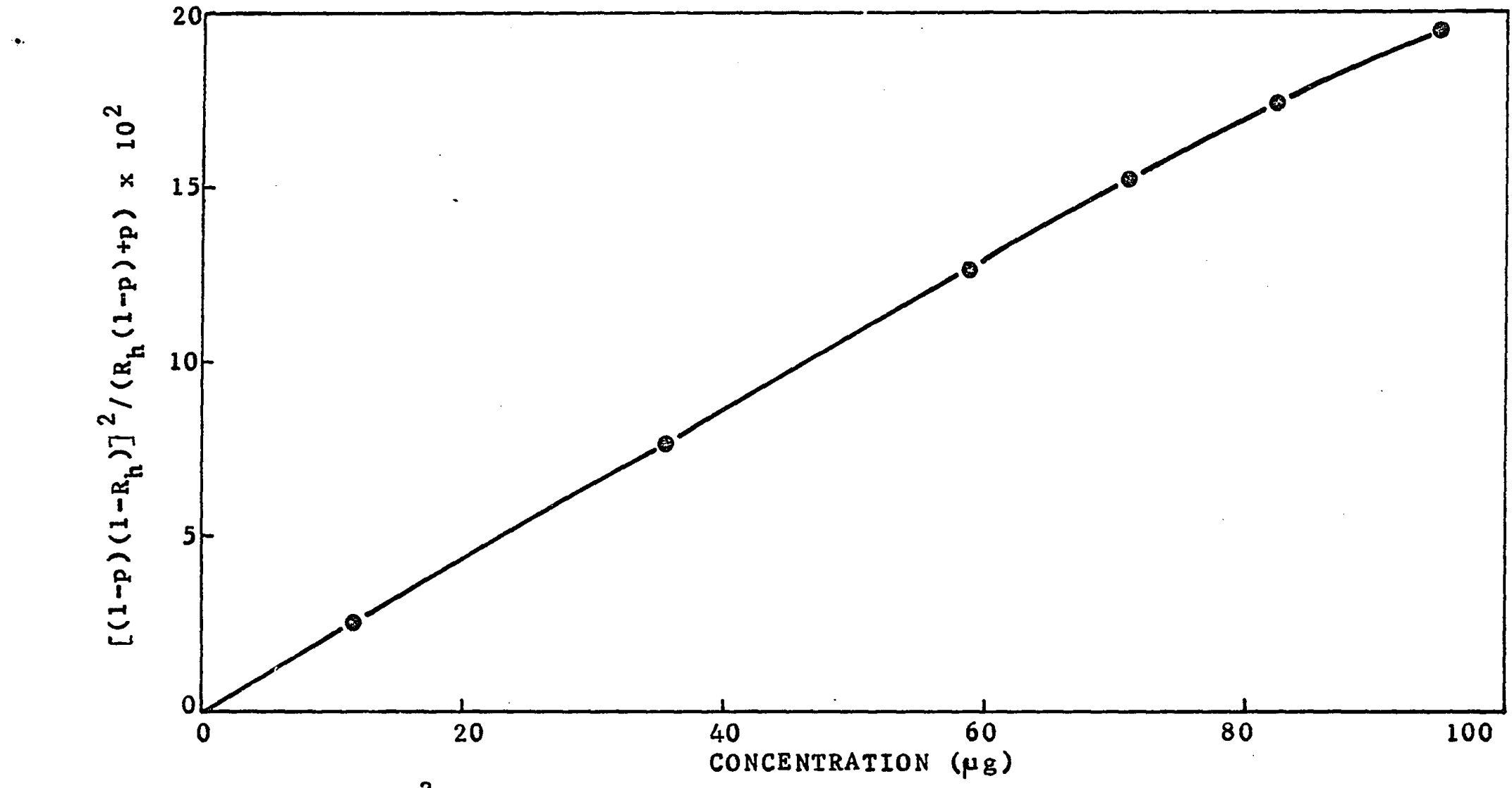

Fig. 10. $\left[(1-p)\left(1-R_{h}\right)\right]^{2} /\left(R_{h}(1-p)+p\right)$ vs. concentration for nicke1-dimethylglyoxime complex adsorbed on cellulose. 


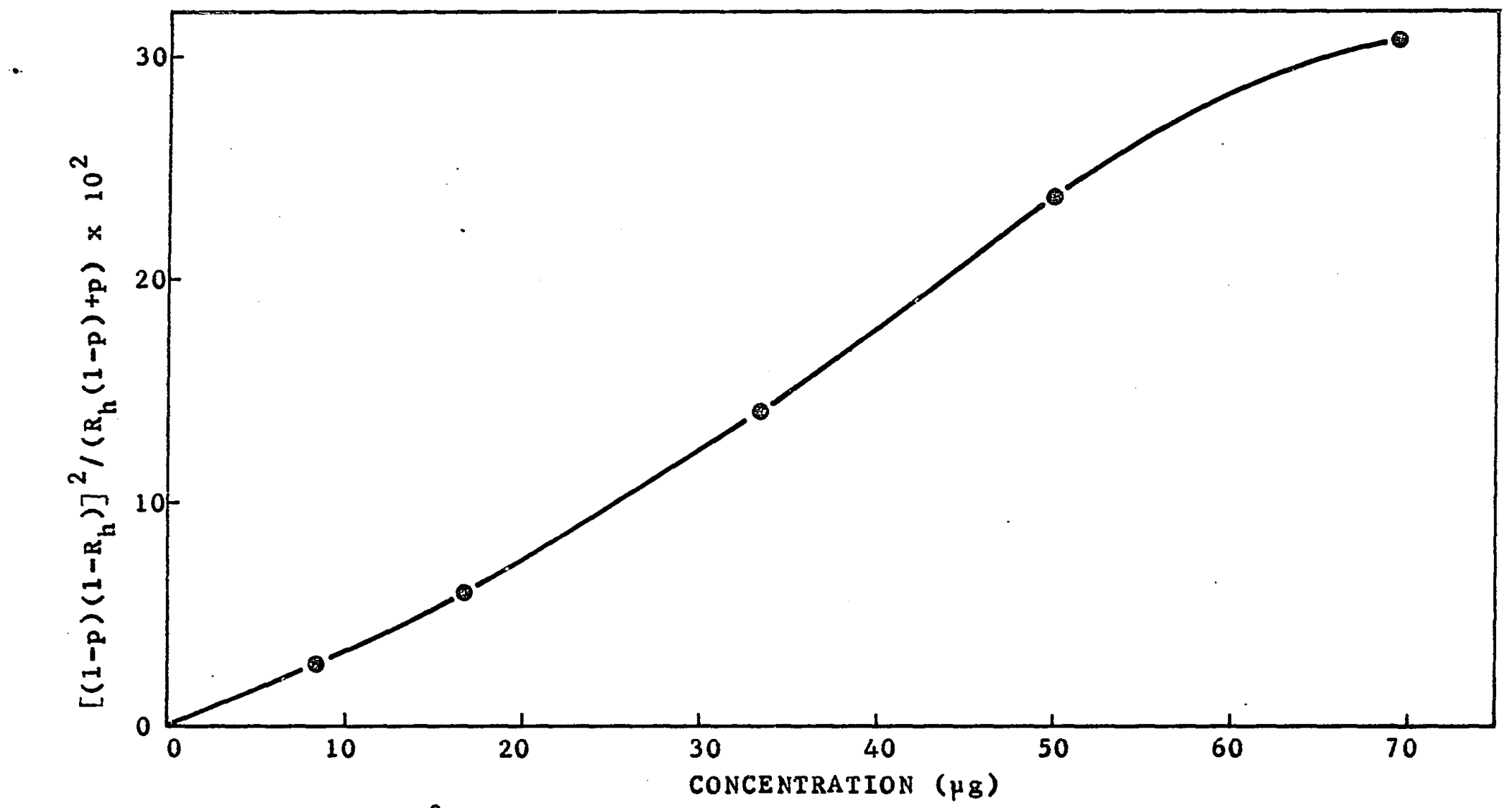

Fig. 11. $\left[(1-p)\left(1-R_{h}\right)\right]^{2} /\left(R_{h}(1-p)+p\right)$ vs. concentration for copper-neocuproine complex adsorbed on cellulose.

$\mathbf{N}$ 


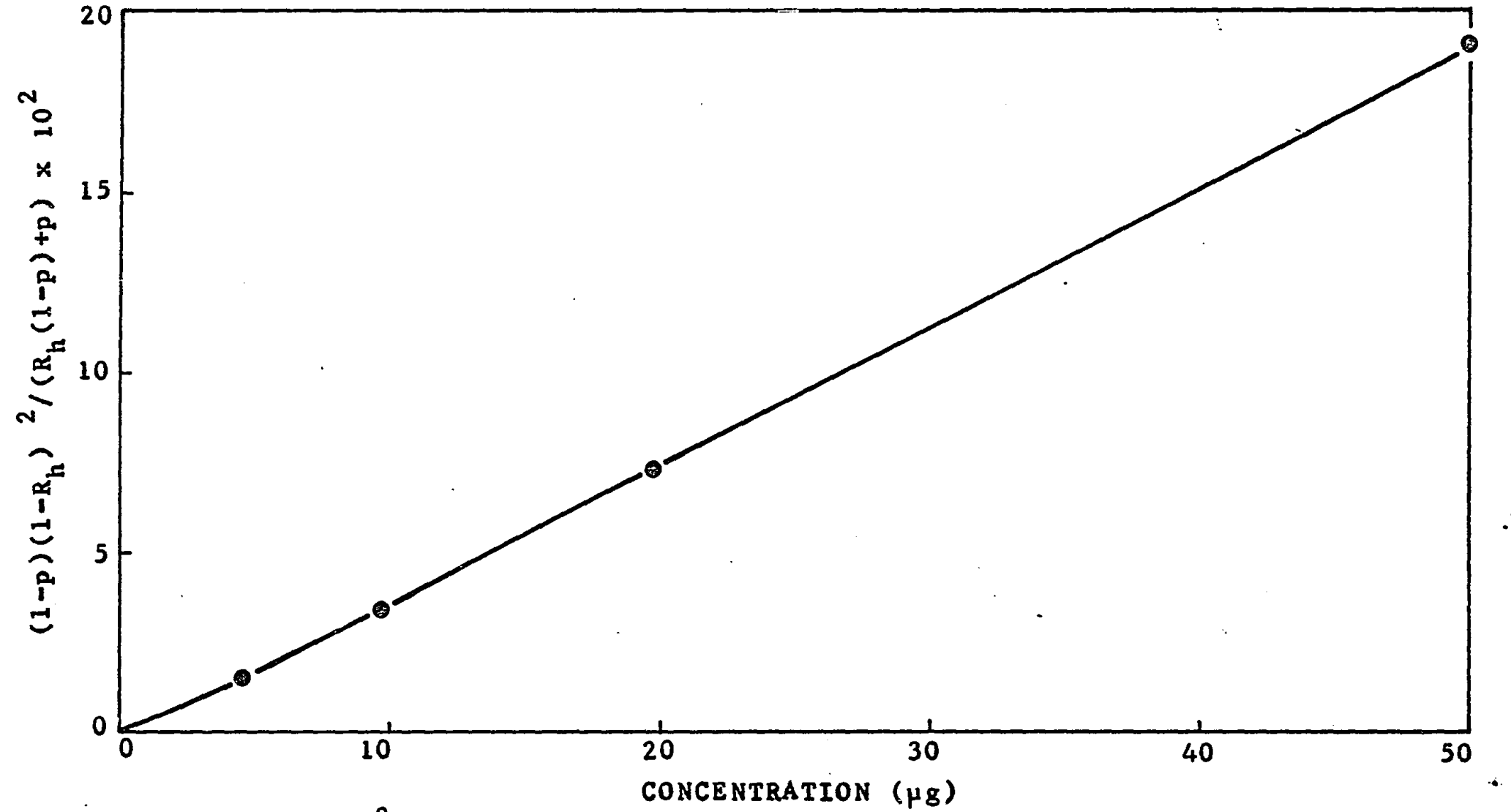

Fig. 12. $\left[(1-p)\left(1-R_{h}\right)\right]^{2} /\left(R_{h}(1-p)+p\right)$ ys. concentration for zinc-naphthidine compound adsorbed on cellulose. 
from a straight line indicating deviation from the $K-M$ equation. Again as predicted, the K-M plots for the high reflectance method are also non-linear.

Regardless of the conformation of a system to the K-M equation, the optimum concentration range for the high reflectance spectrophotometric method of analysis can be deduced by computing the relative error dc/c. Taking the derivative of equation (9) with respect to $R_{h}$, the error in $\mathrm{c}$ is

$$
d c=\frac{k^{\prime}}{2} \frac{(1-p)^{2}\left(1-R_{h}\right)\left(p R_{h}-R_{h}-p-1\right)}{\left(R_{h}(1-p)+p\right)^{2}} d R_{h}
$$

and the relative error in $c$ is then

$$
\frac{d c}{c}=\frac{k^{\prime}}{2 c} \frac{(1-p)^{2}\left(1-R_{h}\right)\left(p R_{h}-R_{h}-p-1\right)}{\left(R_{h}(1-p)+p\right)^{2}} d R_{h}
$$

Assuming an error amounting to one reflectance unit, i.e., $d R_{h}=0.01$, then

$$
\begin{aligned}
\frac{d c}{c} \times 100 & =\frac{k^{\prime}}{2 c} \frac{(1-p)^{2}\left(1-R_{h}\right)\left(p R_{h}-R_{h}-p-1\right)}{\left(R_{h}(1-p)+p\right)^{2}} \\
& =\% \text { error in } c .
\end{aligned}
$$

In the special case where $p=0$, equation (10) is reduced to the form

$$
d c=\frac{k^{*}\left(R_{h}^{2}-1\right) d R_{h}}{2 R_{h}^{2}}
$$


the error in c which has been devised in previous work 63 for the ordinary method. In this work, the authors computed the relative error, dc/c, with the use of the $K-M$ equation, and assuming a reading error of one reflectance unit, calculated the percent error in concentration. By plotting this error against reflectance, they found that the minimum relative error in concentration occurs at a reflectance value of 0.414 , corresponding to a reflectance reading of $41.4 \%$. This is presented graphically in Figure 13. The percent error in concentration can also be computed by making use of equation (12) where $k / 2$ is obtained from the inverse of the slope of the K-M plots in Figures 10 - 12 at concentration $c$ and the constant $p$ is obtained by measurement of the reflectance value of the different standard employing the ordinary method of reflectance measurement. Figures $14-16$ depict the percent error in concentration as a function of percent reflectance for the three cations under study computed by making use of equation (12). The curves are in general agreement with those obtained with the graphical method as are shown in Figures 17 - 19. The scatter in the curves plotted with both methods and the deviations between equivalent plots arise from the methods of calculation.

The optimum ranges in percent reflectance together with their corresponding concentration ranges and the percent error arising from an error of one percent reflec- 


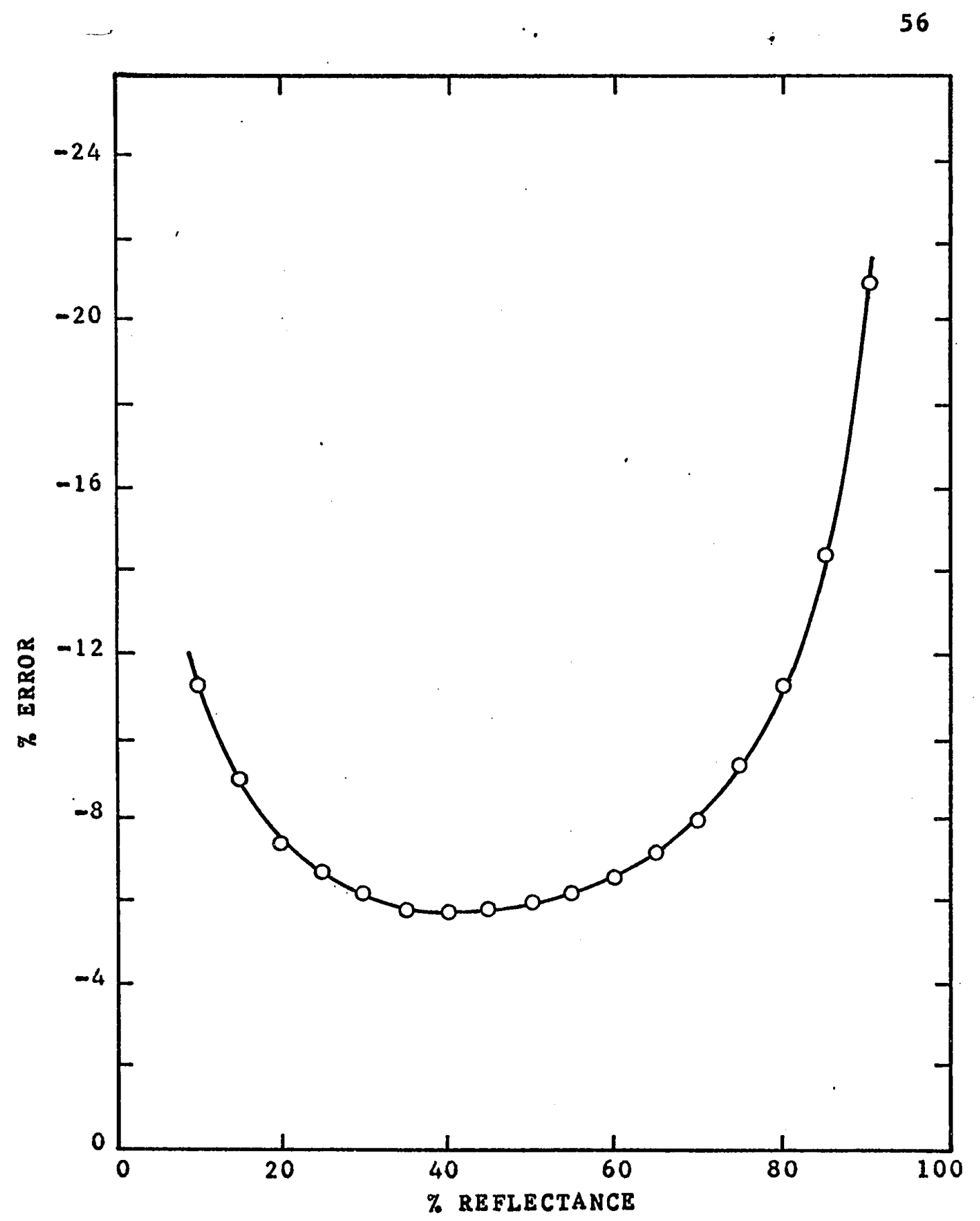

Fig. 13. Percent error as a function of percent refiectance. 


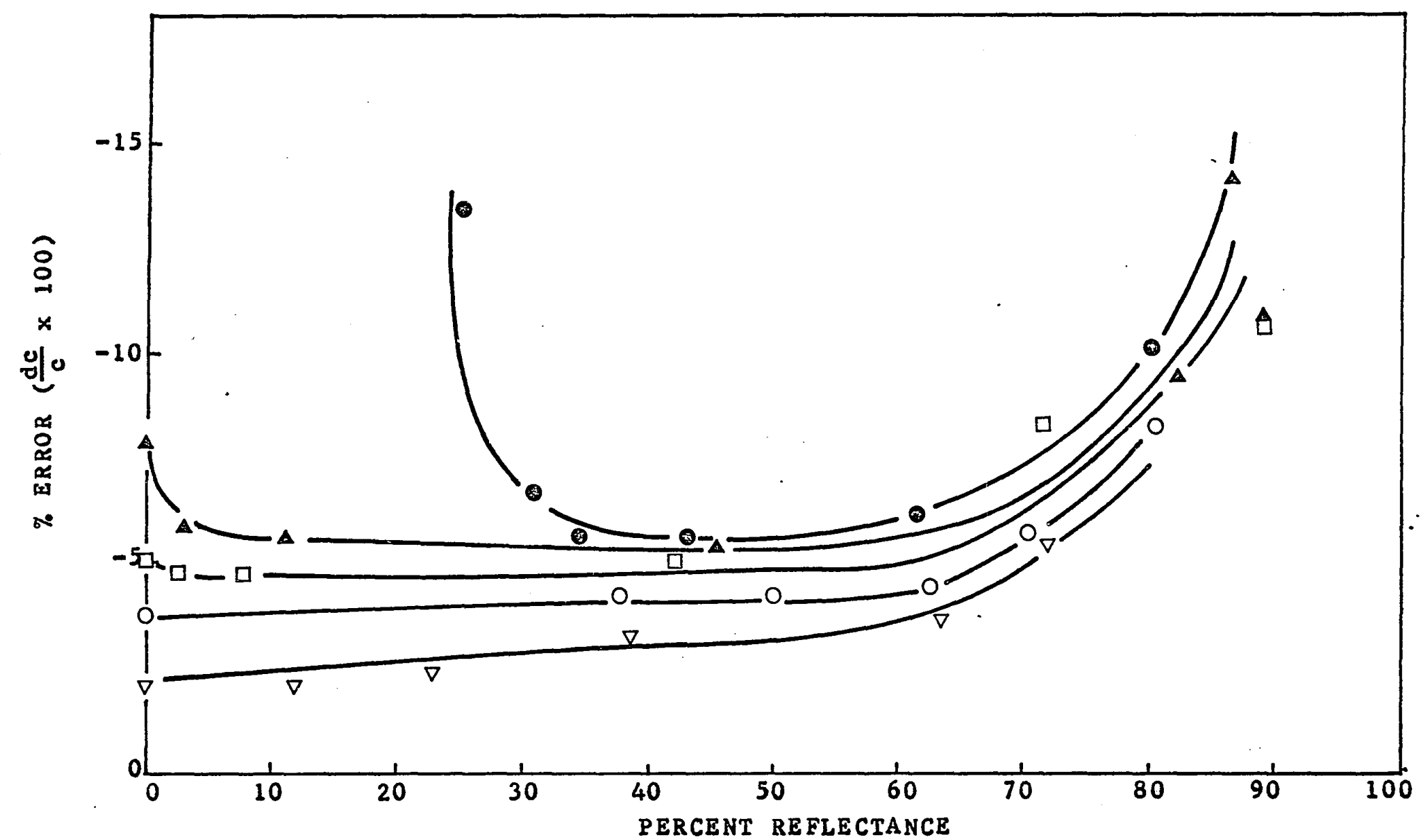

Fig. 14. Percent error arising from an error of $1 \% R$, computed with the use of equation (12), as a function of percent reflectance for nickel-dimethylglyoxime adsorbed on cellulose. Differential standard concentrations ( $\mu \mathrm{g} N 1 / 40 \mathrm{mg}$ cellulose): $\mathrm{photo-}$ cell in darkness $(-), 106.7(\star), 83(-\square), 59.3(-0), 5.9(-))$. 


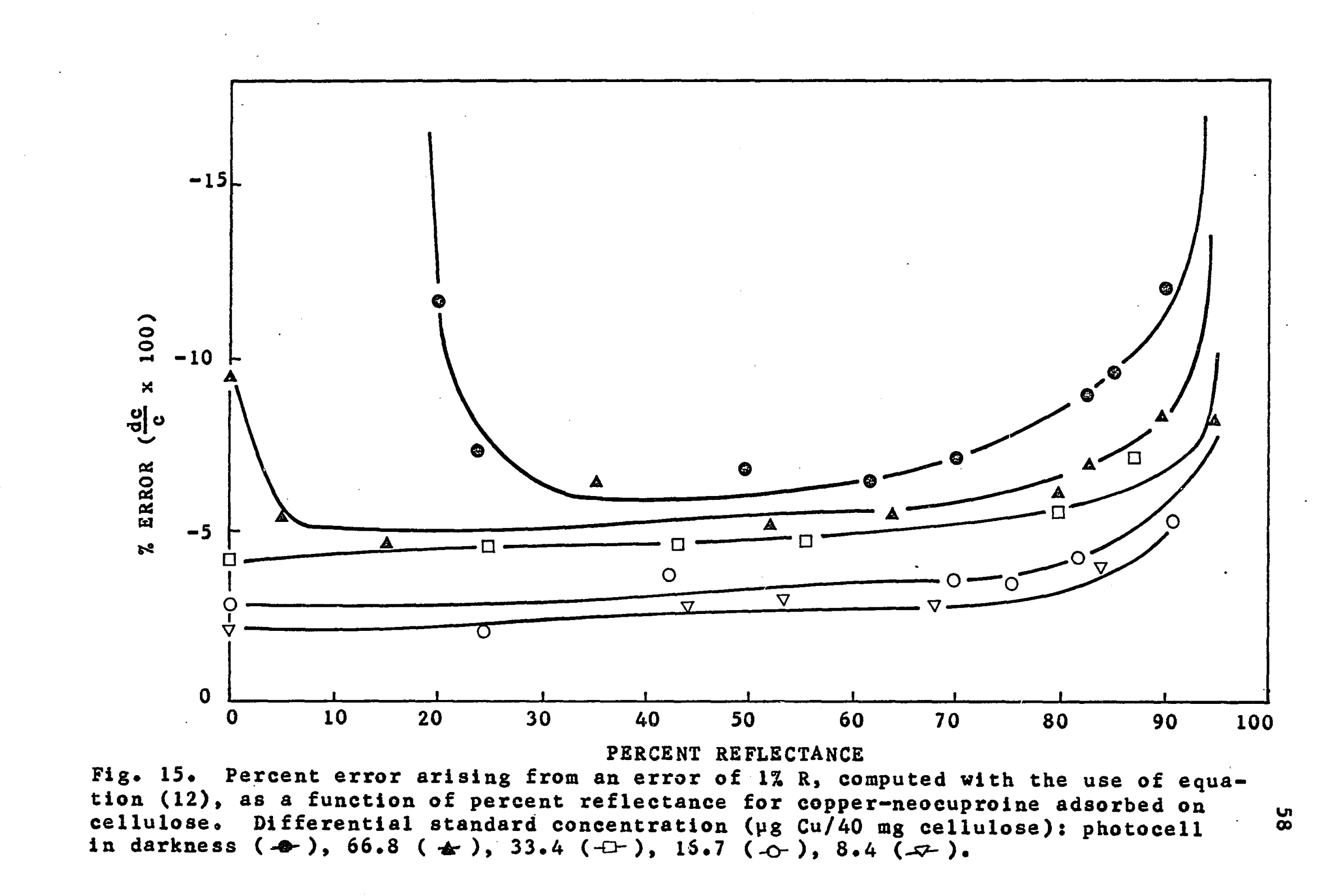




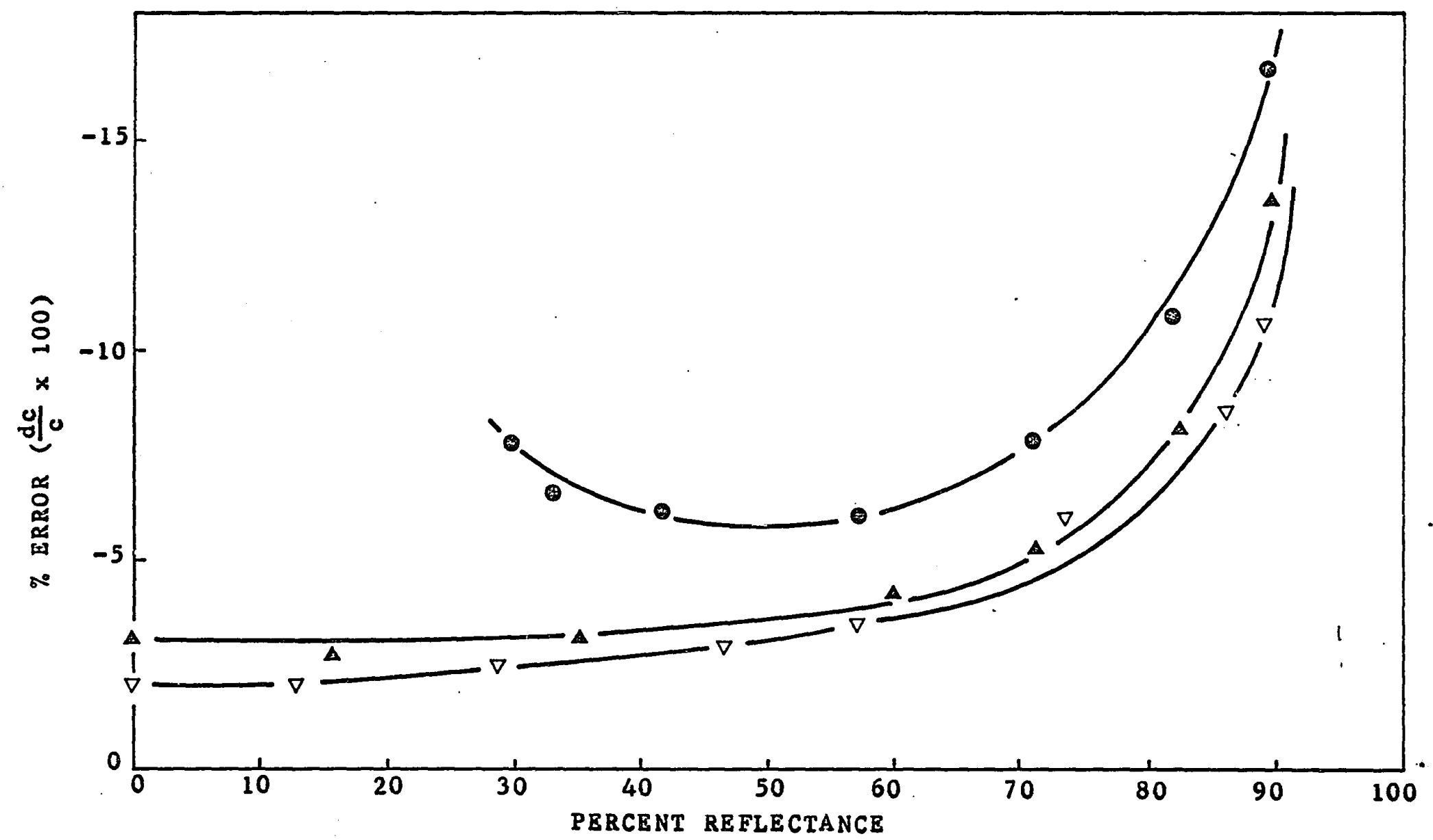

Fig. 16. Percent error arising from an error of $1 \% R$, computed with the use of equation (12), as a function of percent reflectance for zinc-naphthidine adsorbed on cellulose. Differential standard concentrations ( $\mu \mathrm{g} \mathrm{zn} / 40 \mathrm{mg}$ cellulose): photocell in darkness $(-), 50(\star), 20(-\infty)$. 


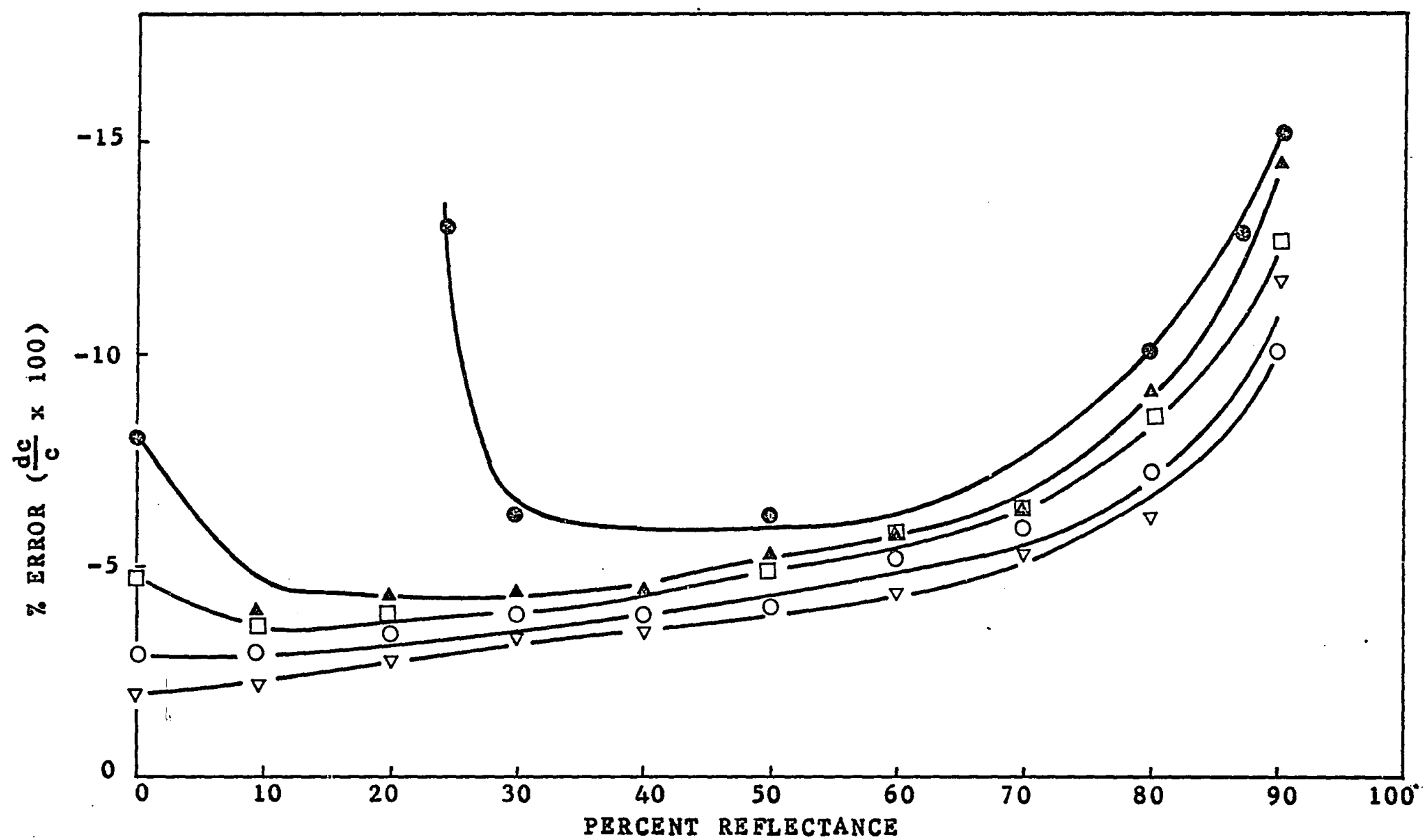

Fig. 17. Percent error arising from an error of 1\% R (estimated graphically) as a function of percent reflectance for nickel-dimethylglyoxime adsorbed on cellulose. Differential standard concentrations ( $\mu \mathrm{g} \mathrm{N} / 40 \mathrm{mg}$ cellulose): photocell in darkness $(\rightarrow), 106.7(\star), 83(-\square), 59.3(-0), 5.9(-\neg)$.

g 


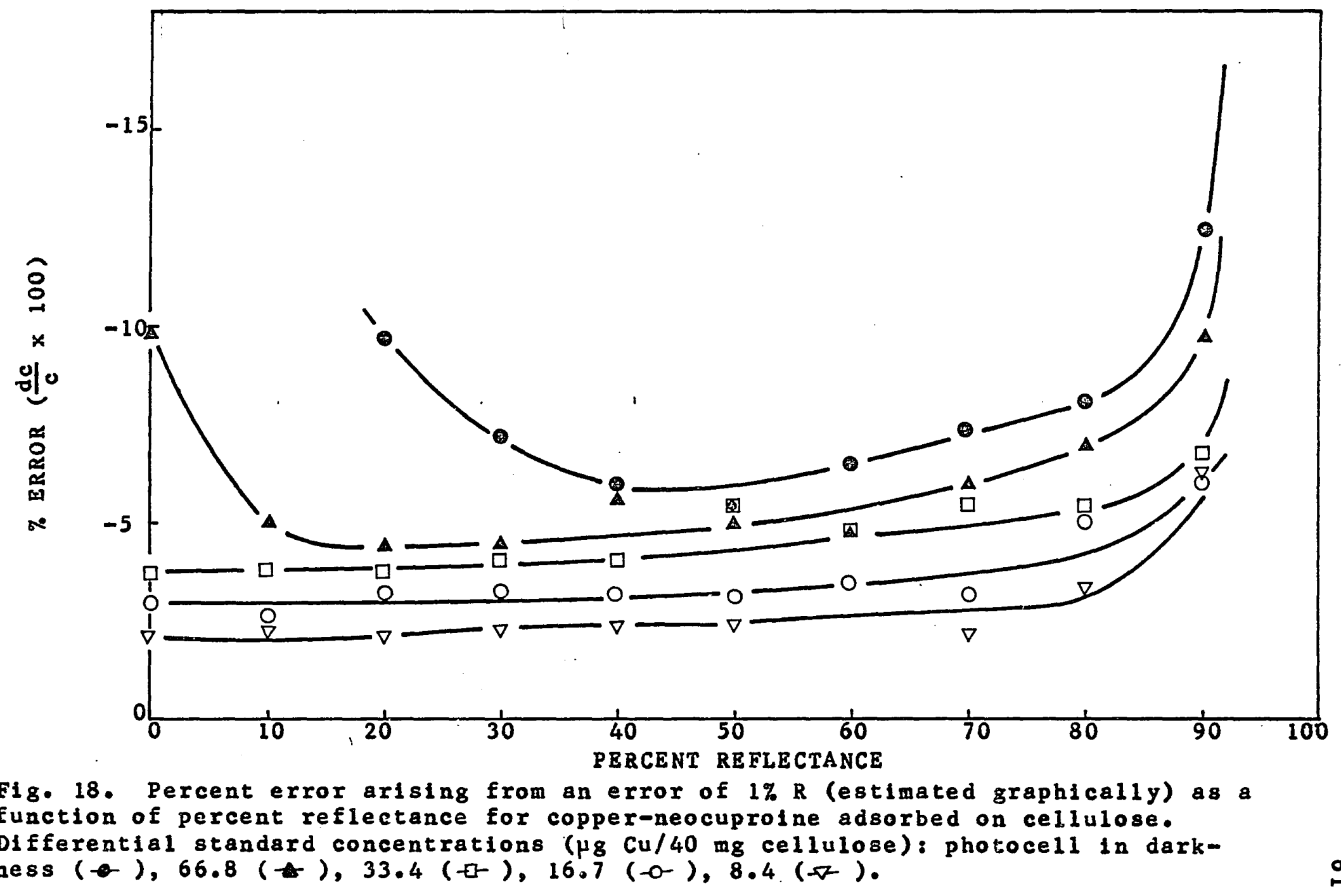




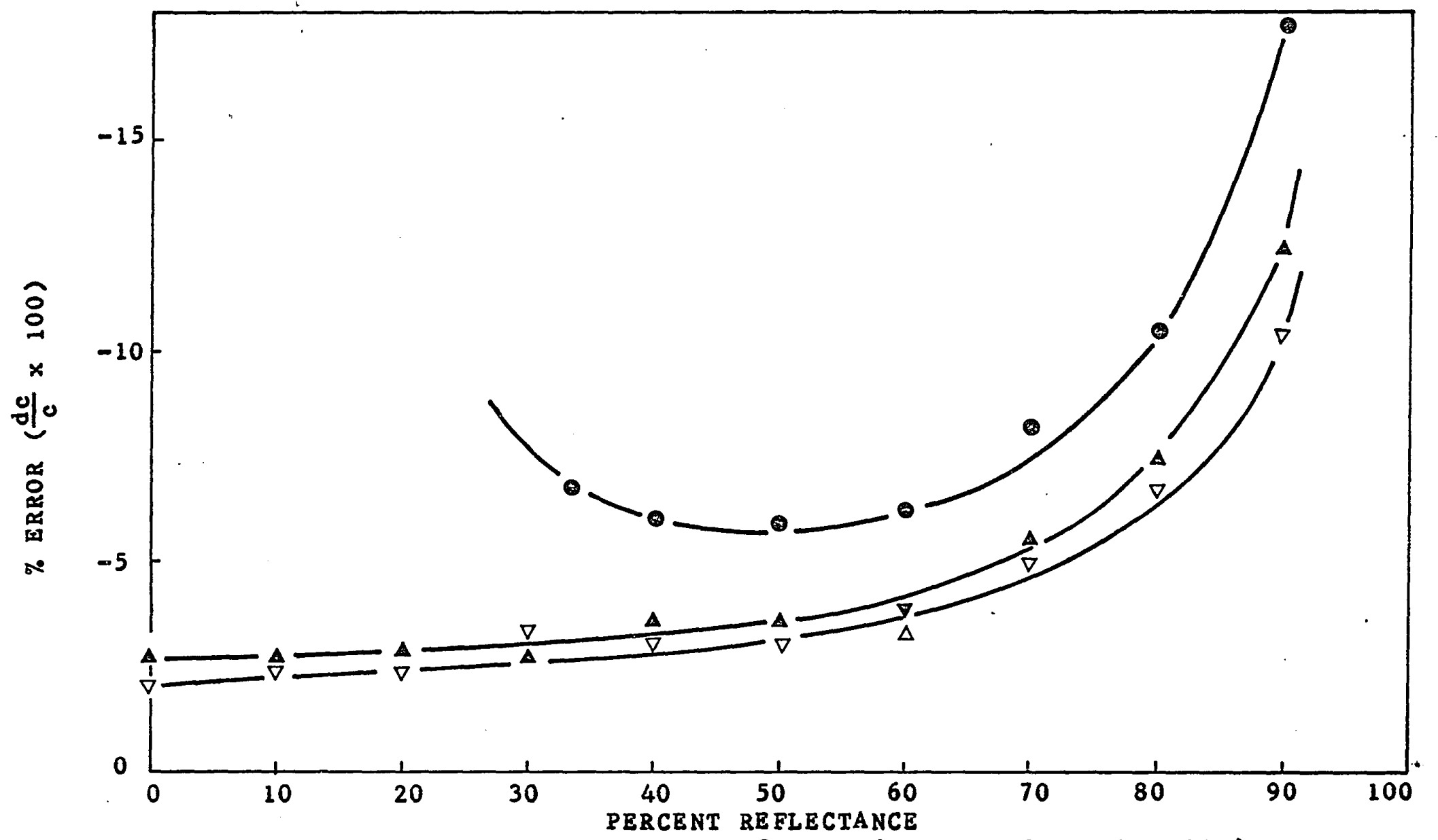

Fig. 19. Percent error arising from an error of $1 \%$ R (estimated graphically) as a funetion of percent reflectance for zinc-naphthidine adsorbed on cellulose. Differential standard concentrations ( $\mu \mathrm{g} \mathrm{zn} / 40 \mathrm{mg}$ cellulose): photocell in darkness $(-), 50(-), 20(-\nabla)$. 
tance for the three systems are summarized in Table $V$. As can be seen from the table, the application of the high reflectance method entails the following advantages in comparison to the ordinary method: 1) The lower limit of the optimum reflectance range for anatysis is extended from $30 \% \mathrm{R}$ in the ordinary method to lowex reflectance values which approach $0 \% R$ with the use of the bigh reflectance method. 2) The lower limit of the optimum concentration range is extended with a decrease in concentration of the differential standard. In the case of zinc, the lower limit is extended from $12 \mu g \mathrm{zn} / 40 \mathrm{mg}$ cellulose in the ordinary method to $1.1 \mu \mathrm{g} \mathrm{zn} / 40 \mathrm{mg}$ cellulose with the employment of $20 \mathrm{Hg} \mathrm{zn} / 40 \mathrm{mg}$ cellulose sample as the differential standard. This is a reduction of ll-fold in concentration. Likewise a 4-fold and 5-fold reduction in concentration can be obtained in the cases of copper and nickel respectively. This method is thus more sensitive than the ordinary method of reflectance spectroscopy. 3) In the relatively high concentration range the percent error arising from an error of $1 \%$ R decreases with a decrease in the concentration of the differential standard. By judiclous choice of differential standard, the exror can be materially reduced. For example, the percent error in the analysis of $5.0 \mu \mathrm{N} / / 40 \mathrm{mg}$ cellulose is about $-7 \%$ in the ordinary method. By employing a $5.9 \mu \mathrm{Ni} / 40 \mathrm{mg}$ cellulose sample as a differential standard, the error is 
Table V

Optimum Percent Reflectance and Concentration Ranges for Analysis and Percent Brror

\begin{tabular}{|c|c|c|c|c|c|c|c|c|c|}
\hline \multirow{2}{*}{$\begin{array}{l}\text { System C } \\
\text { Nicke1- } \\
\text { Dimethyl- } \\
\text { glyoxime }\end{array}$} & $\begin{array}{l}\text { ncentration of } \\
\text { erential Standard } \\
(40 \text { mg cellulose) }\end{array}$ & \multicolumn{2}{|c|}{$\begin{array}{c}\text { Optimum Reflectance } \\
\text { Range } \\
(\% R) \\
\end{array}$} & \multicolumn{2}{|c|}{$\begin{array}{c}\text { Optimum Concentration } \\
\text { Range } \\
\text { ( } \mathrm{\mu g} / 40 \mathrm{mg} \text { cellulose) }\end{array}$} & \multicolumn{3}{|c|}{$\begin{array}{r}\text { \% Analysis } \\
\text { Per } \\
\text { Error of } \\
\end{array}$} & $\begin{array}{l}\text { Error } \\
1 \% R \\
\end{array}$ \\
\hline & $\begin{array}{c}5.9 \\
59.3 \\
83.0 \\
106.7 \\
\text { photocell in } \\
\text { darkness }\end{array}$ & $\begin{array}{r}0 \\
0 \\
0 \\
5 \\
30\end{array}$ & $\begin{array}{l}-70 \\
-70 \\
-70 \\
-70 \\
-70\end{array}$ & $\begin{array}{l}5.9 \\
59.3 \\
83.0 \\
76 \\
76\end{array}$ & $\begin{array}{l}=0.9 \\
=1.3 \\
=2.3 \\
-3.0 \\
-5.0\end{array}$ & $\begin{array}{l}-5 \\
-6\end{array}$ & $\begin{array}{l}-2 \\
-3 \\
\text { to } \\
\text { to } \\
-6\end{array}$ & $\begin{array}{l}\text { to } \\
\text { to } \\
-4 \\
-5 \\
\text { to }\end{array}$ & 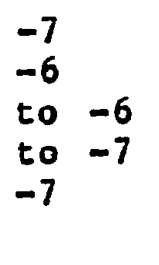 \\
\hline $\begin{array}{l}\text { Copper- } \\
\text { Neocup- } \\
\text { roine }\end{array}$ & $\begin{array}{c}8.4 \\
16.7 \\
33.4 \\
66.8 \\
\text { photocel1 in } \\
\text { darkness }\end{array}$ & $\begin{array}{r}0 \\
0 \\
0 \\
10 \\
30\end{array}$ & $\begin{array}{l}-80 \\
=80 \\
=80 \\
=80 \\
-80\end{array}$ & $\begin{array}{l}8 \cdot 4 \\
16 \cdot 7 \\
33 \cdot 4 \\
40 \\
36\end{array}$ & $\begin{array}{l}-0.5 \\
-1.0 \\
-1.2 \\
-1.5 \\
-2.0\end{array}$ & -7 & $\begin{array}{l}-2 \\
-3 \\
-4 \\
-6 \\
\text { to }\end{array}$ & $\begin{array}{l}\text { to } \\
\text { to } \\
\text { to } \\
\text { to } \\
-6\end{array}$ & 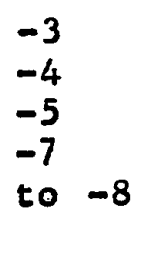 \\
\hline $\begin{array}{l}\text { Zinc- } \\
\text { Dimethyl- } \\
\text { naphthidine }\end{array}$ & $\begin{array}{l}20.0 \\
50.0 \\
\text { photocell in } \\
\text { darkness }\end{array}$ & $\begin{array}{r}0 \\
0 \\
\text { ca. } 30\end{array}$ & $\begin{array}{l}-80 \\
-80 \\
-80\end{array}$ & $\begin{array}{r}20.0 \\
50.0 \\
\text { ca. } 200\end{array}$ & $\begin{array}{l}-1 \cdot 1 \\
-2 \cdot 1 \\
-12\end{array}$ & & $\begin{array}{l}-2 \\
-3 \\
-6\end{array}$ & $\begin{array}{l}\text { to } \\
\text { to } \\
\text { to }\end{array}$ & $\begin{array}{l}-6 \\
-7 \\
-8\end{array}$ \\
\hline
\end{tabular}


reduced to about $-2 \%$. This is a reduction of $3 \frac{1}{2}-$ fold in error. Similar decreases also can be obtained in the cases of copper and zinc. Reduction in percent error with reduction in concentration of differential standard is most noticeable in the case of the copper-neocuproine complex. Perhaps this can be ascribed to the high value of the molar absorption coefficient of this system. In order to minimize the error, therefore, it is suggested that the analysis be made in the high concentration region of the optimum range, i.e., a sample with a concentration somewhat higher than that of the unknown be selected as the differential standard.

It would seem, therefore, that with the application of the high reflectance method it is possible to determine samples of very low concentration with an error no greater than $-7 \% / 1 \% R$, and also enables the analysis of samples of low concentrations with an error as 10 as $-2 \% / 1 \%$ R. The error in percent reflectance generally encountered in reflectance measurement is of the order of $0.3 \%$ and this amounts to about $-2 \%$ and $-0.6 \%$ error respectively.

It has been assumed that $\mathrm{dR}_{h}$ is independent of $R_{h}$ and the differential standard employed. The validity of the assumption has been tested experimentally. Samples of nickel-dimethylglyoxime covering a wide range of concentrations were prepared. A series of reflectance measurements were made using samples of $70,35,25$, and 
1.0 yg as differential standards and in each series, measurements were made on samples of such varied concentration so that the complete reflectance scale is covered. Several measurements were made for each sample in each series without disturbing the geometry. The standard deviations of replicate measurements for all samples with each differential standard fell randomly in the range of 0.1 to $0.3 \% \mathrm{R}$.

D. The Application of Reflectance Spectroscopy to the Analysis of Some Trace Metal Cations in Sea Water The amounts of trace metals in sea water are of considerable blological and geological importance; $91-94$ and although the estimation of these concentrations has been of interest since the early 19 th century, precise methodology is iacking even today. This is partly due to the concentrations of these metals in the ocean-- frequently in the parts per billion range-- and the experimental difficulties associated with such measurements.

The determination of trace metal cations in sea water usually requires the processing of relatively large volumes of sample by techniques which not only concentrate the cations but also diminish the number of interferences. Solvent extraction has been used successfully for preconcentration in sea water analysis by a number of investigators.95-99 Multi-element extraction is particularly 
useful because of the speed and wide scope of the method. Repetitive extractions can augment the efficiency with which the metals are isolated, and removal of the extracted solvent may be easily accomplished by acid treatment. When several metal cations are to be determined, it is advantageous to carry out a multi-element extraction followed by separation and determination by thin-layer chromatography. If selective reagents were used to isolate and concentrate metals from sea water, not only would the experimental cunditions be more stringent to preclude interferences, but a separate sample and different procedure would be required for each ton.

It was decided to demonscrate the feasibility of this approach and the analytical utility of the spectral reflectance method by analyzing for three cations, copper, nickel, and zinc, which are of significance in blology and geology.100-103 Each of the three metal cations can be extracted from aqueous solution by dithizone: copper in a slightly acid medium and zinc and nick from an ammoniacal solution. Because dithizone is a non-specific extractant, other metal cations accompanied those under investigation. In dilute mineral acid solution, copper reacts with dithizone to form a redmiolet complex extractable into carbon tetrachloride. Under these same conditions gold, palladium, silver, and mercury are also extracted.85 This water sample was then adjusted to a $\mathrm{pH}$ of arrpoximately 8 
with ammonia, and dithizone in carbon tetrachloride was again used to extract the nickel and zinc. 82 Again the extraction is not selective since lead, cobalt, cadmium, and to some extent bismuth also form dithizonates at this pH. The organic extracts containing the metal complexes were combined and the metals under investigation were back-extracted into the aqueous phase with hydrochloric acid. The usual method 104 for decomposing the copper dithizonate and transferring it to the aqueous phase is rather tedious; but Friedberg ${ }^{105}$ has found that shaking the complex with $6 \mathrm{~N}$ hydrochloric acid accomplishes the stripping of the organic phase rapidly and quantitatively. Because the concentrations of the metals in sea water are so low, special precautions are necessary to avold contamination. Although common acids of reagent quality are as a rule very 100 in heavy metals, 85 hydrochloric acid sometimes contains appreciable traces of mercury. For this reason is was necessary to distill this reagent prior to use.

It can be seen from Table I that mercury and cadmium have $R_{f}$ values similar to zinc when chromatographed on cellulose plates in a mixture of butanol and hydrochloric acid. Both of these cations also give a color reaction with the chromogenic reagent employed for the zinc analysis. But a comparison of the concentrations of these metals in sea water to that of $z^{1 n c^{92}}$ show that the amounts 
of mercury and cadmium are approximately 1000 and 100 times, respectively, less than zinc. The amount of zinc chromatographed from the sea water is such that the concentrations of these possible interferences are beyond the limit of detection with the chromogenic reagent for zinc. The concentrations and $R_{E}$ values of the other extracted cations also preclude interference from these in the determination of nickel and copper as well as zinc.

An attempt was first made to determine copper, nickel, and zinc in sea water by the ordinary method of spectral reflectance, i.e., the zero adjustment of the spectrophotometer is made with the photocell in darkness and the scale set to read 100 with adsorbent from the plate under investigation. For the calibration plots, $\left(1-R_{\infty}\right)^{2} / 2 R_{\infty}$ was plotted against concentration, the form of the Kubelka-Munk expression most often used, and curves similar to those in Figures 10 through 12 resulted. Metal cations from one liter of sea water were extracted as explained previously, and a $300 \mathrm{ml}$ aliquot of this, after appropriate treatment, subsequently chromatographed and analyzed. These results are shown in Table VI. Concentrations of the three metals approximating those found in sea water were than added to replicate sea water samples in order to ascertain the efficiency of the experimental procedures, and the reflectance values also measured. These data are presented in Table VII. It can be seen 
Table VI

Determination of Copper, Nickel, and Zinc in $300 \mathrm{ml}$

Sea Water Employing the Ordinary Method of

Reflectance Spectroscopy

$\begin{array}{lcccc}\text { Cation } & \begin{array}{c}\text { Reflectance } \\ (\% R)\end{array} & \begin{array}{c}\text { Concentration } \\ (\mu g / 300 \text { ml })\end{array} & \begin{array}{c}\text { Analysis Error / } \\ \text { Error of } 1 \% R\end{array} \\ \text { Copper } & 86.9 & 0.78 & -10 \\ \text { Nicke1 } & 88.0 & 0.37 & -14 \\ \text { Zinc } & 95.1 & 1.5 & -\ldots\end{array}$


Table VII

\begin{abstract}
Determination of Copper, Nickels and Zinc in $300 \mathrm{ml}$
Enriched Sea Water Employing the Ordinary Method of Reflectance Spectroscopy
\end{abstract}

$\begin{array}{lcccc}\text { Cation } & \begin{array}{c}\text { Concentration of } \\ \text { Metal Added } \\ (\mu g / 1)\end{array} & \begin{array}{c}\text { Reflectance } \\ (\% \mathrm{R})\end{array} & \begin{array}{c}\text { \% Analysis Error / } \\ \text { Error of } 1 \% \mathrm{R}\end{array} \\ \text { Copper } & 6.67 & 76.6 & -7.5 \\ \text { Nickel } & 3.33 & 82.4 & -11 \\ \text { Zinc } & 10.00 & 93.3 & -\ldots\end{array}$


from the error curve deduced by computing the relative error, dc/c, as a function of reflectance that for the ordinary method of analysis zinc cannot be determined without resulting in large error since the percent reflectance values lie in a range where the relative error rises sharply (see Figure 19). An inspection of Figures 17 and 18 and the data in Tables VI and VII for copper and nickel indicate that the relative errors in concentration obtained with the enriched samples are about $3 \%$ lower than on the untreated sea water samples. However, these values are still greater than the errors which are achieved by measurement of the concentrations in the optimum reflectance range for analysis. Hence in order to obtain more accurate measurements of these metal cations, a lárger sea water sample would have to be used for the determination. However, approximately 71 ters would be required in order to obtain a sufficient concentration of these metal cations such that readings could be made in the optimum reflectance range. In addition to being timeconsuming, the methodic errors associated with the use of larger volumes also increase.

In view of the difficulties encountered with the ordinary method in measuring low concentrations, it was decided to use a differential approach. Not only could a convenient sample size be employed, but more precise measurements could also be attained. As polnted out in 
the previous section, the criteria for minimizing the relative error in the measurement of concentration using the differential technique is the selection of a differential standard whose concentration is somewhat greater than the unknown. In carrying out these analyses, however, the limiting factor was found to be the zeroing of the spectrophotometer as the concentration of the differential standard decreased. Calibration curves employing differential standards, where the function $F\left(R_{\infty}\right)=$ $\left(1-R_{\infty}\right)^{2} / 2 R_{\infty}$ is graphed against concentration, are shown In Figures $20-22$. Again, conformity to the KubelkaMunk equation is noted in the case of nickel, but a slight deviation occurs in the cases of copper and zinc. The data obtained for the determination of the concentration of these three metal cations in sea water employing differential standards are summarized in Table VIII. Similarly, the results for the measurement of the enriched sea water samples are presented in Table IX. By comparing the percent analysis error obtained by the ordinary method with those employing a differential standard, it can be seen that an approximate 5-fold decrease occurs with copper and nickel. In the case of zinc, the readings obtalned in the ordinary method were subject to a much greater error than those in which a differential standard was employed giving rise to a $5 \%$ analysis exror. In order to determine the effectiveness of the experi- 


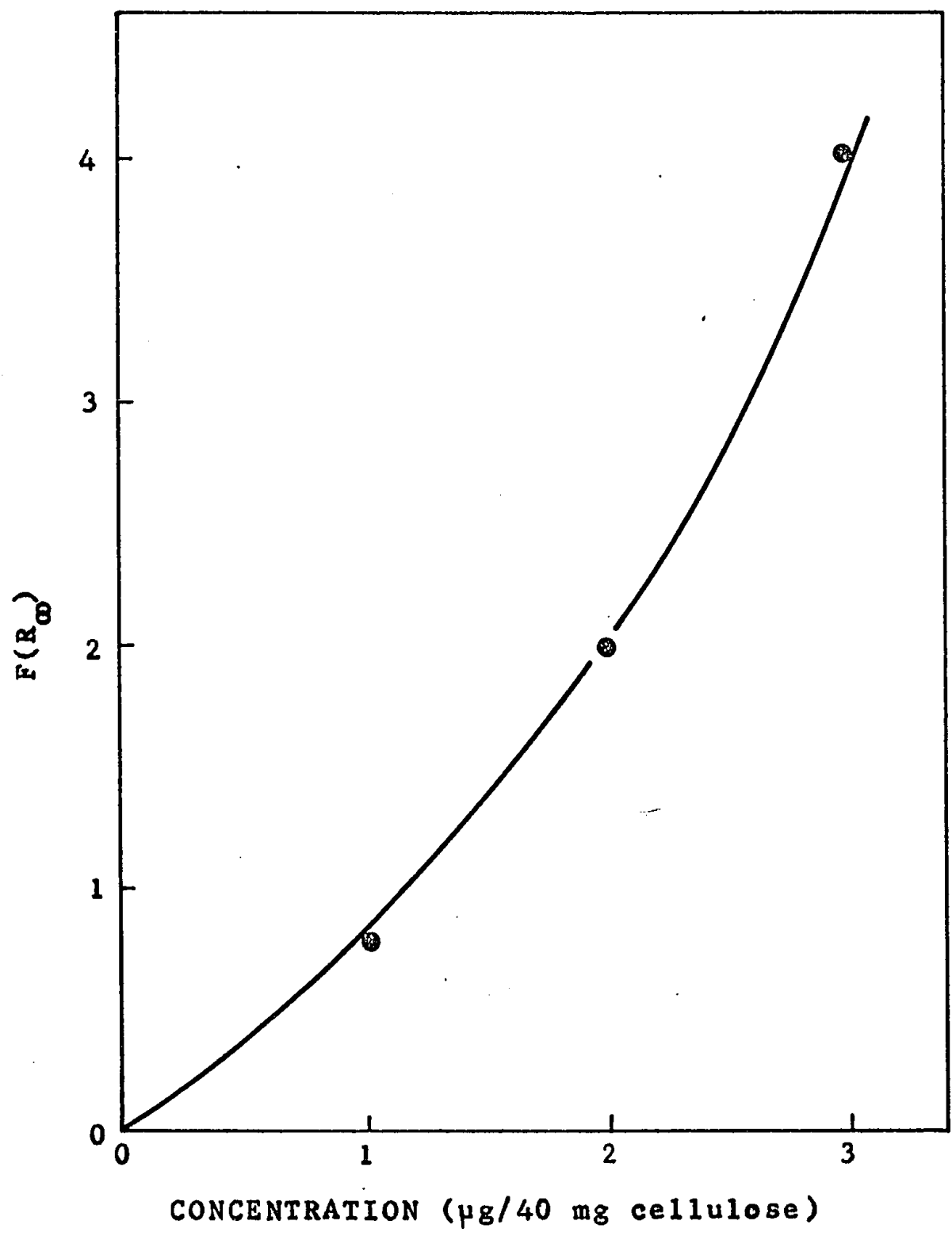

Fig. 20. Kubelka-Munk values at $448 \mathrm{mp}$ for copperneocuproine adsorbed on cellulose as a function of concentration employing a $5 \mu \mathrm{C} \mathrm{Cu} / 40 \mathrm{mg}$ cellulose reference standard. 


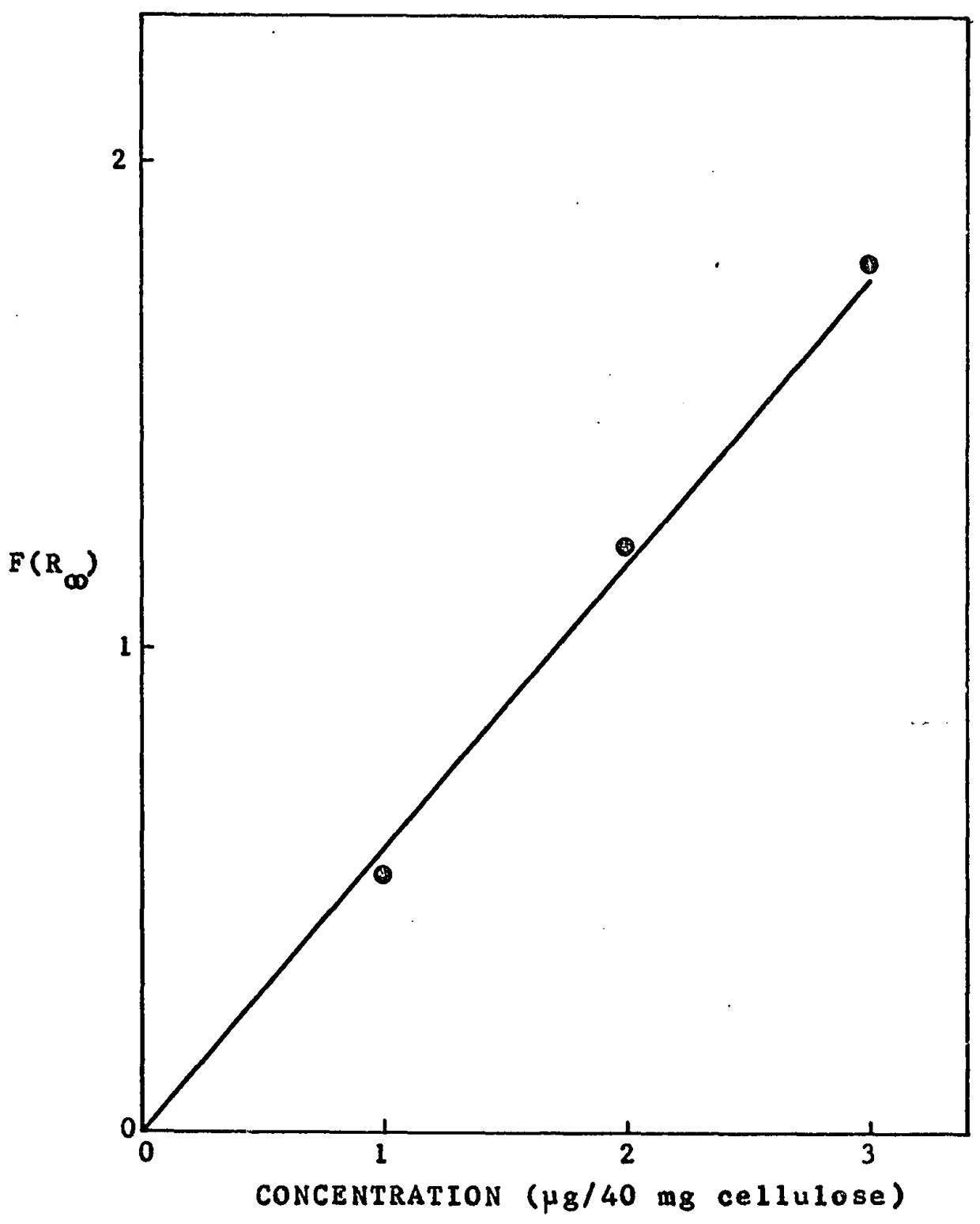

Fig. 21. Kubelka-Munk values at $540 \mathrm{~m} \mu$ for nicke1dimethylglyoxime adsorbed on cellulose as a function of concentration employing a $5 \mu \mathrm{N} / 40 \mathrm{mg}$ cellulose reference standard. 


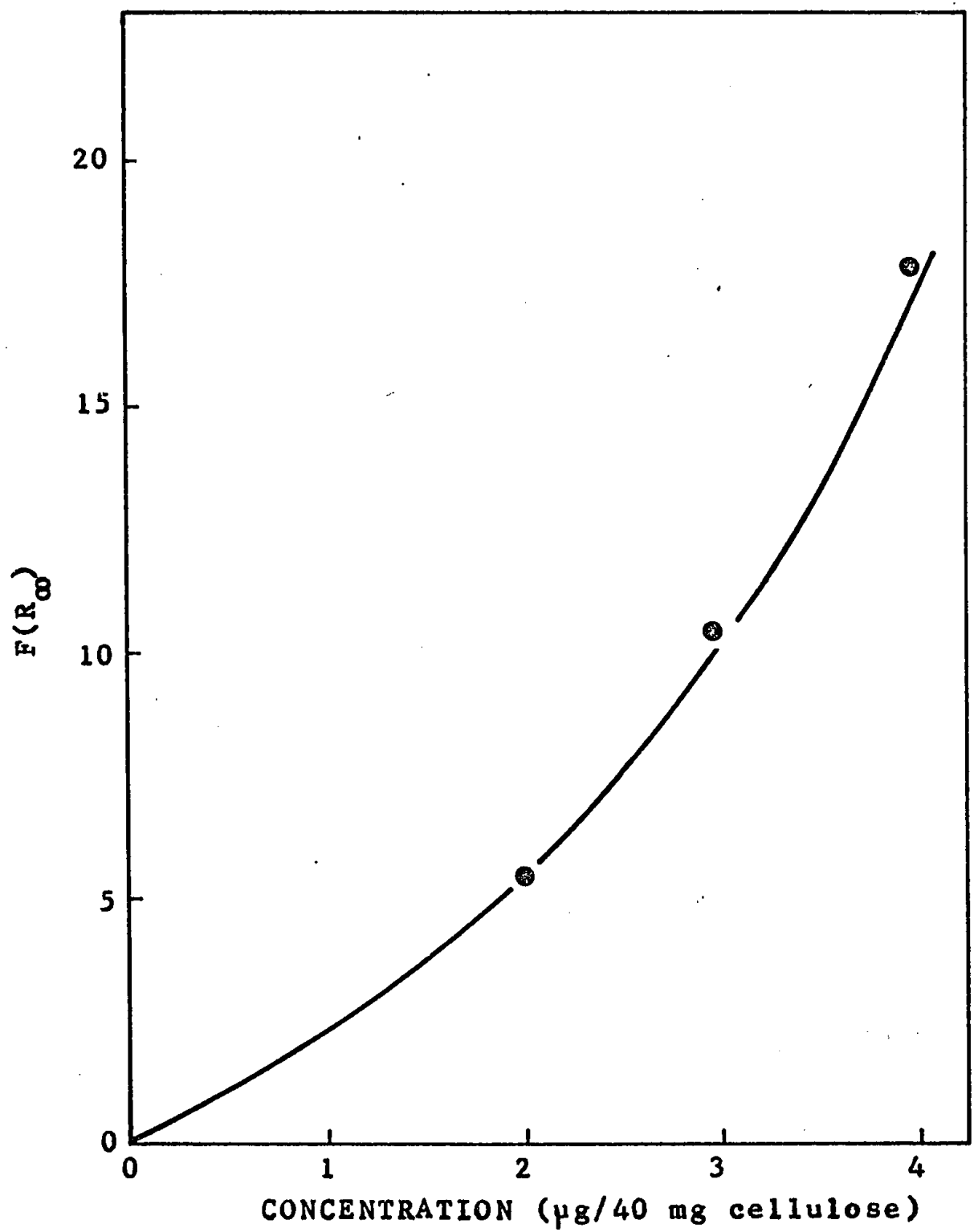

F18. 22. Kubelka-Munk values at 565 mp for zinc-naphthidine adsorbed on cellulose as a function of concentration employing a $20 \mathrm{Hg} \mathrm{zn} / 40 \mathrm{mg}$ cellulose reference standard. 
Table VIII

Determination of Copper, Nickel, and Zinc in $300 \mathrm{ml}$ Sea Water Employing the High Reflectance Method of Differential Spectroscopy

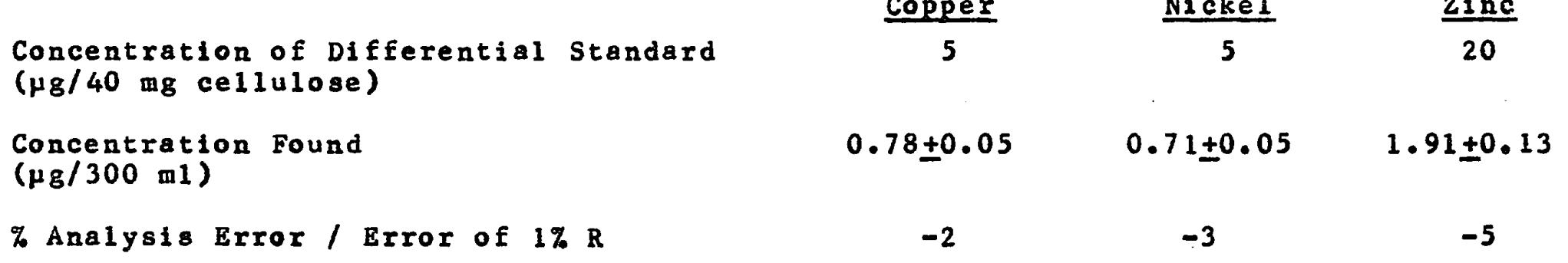


Table IX

Determination of Copper, Nickel, and Zinc in 300 ml Enriched Sea Water Employing the High Reflectance Method of Differential Spectroscopy

Concentration of Differential Standard ( $\mu \mathrm{g} / 40 \mathrm{mg}$ cellulose)

Concentration of Metal Cation Added $(\mu \mathrm{g} / 300 \mathrm{ml})$

Concentration Found $(\mu \mathrm{g} / 300 \mathrm{~m} 1)$

\% Analysis Error / Error of $1 \%$ R
Copper

5

2.0

1.0

$1.65 \pm 0.10$

$4.77 \pm 0.28$

$2.68 \pm 0.14$

$-1.5$

$-2.5$

$-3.5$ 
mental procedures, sea water samples were enriched with the three metal cations and then analyzed. By comparing the data presented in Tables VIII and IX, it can be seen that recoveries of $93 \%, 95 \%$, and $93 \%$ were obtained for copper, nickel, and zinc respectively. The losses may be ascribed primarily to the transfer to the chromatoplates of the sea water samples. Losses due to the extraction procedure may also account for the percentages obtained. This recovery study is based on the addition and subsequent determination of the divalent cations. Most of the dissolved metal, however, is in the form of the extractable cation. Although other oxidation states of nickel and zinc are rare, 106 copper (I) is very common. In studies carried out by Brooks et al. 107 on the determination of copper in sea water by extraction and atomic absorption spectrometry, they treated one of two Identical samples with bromine water to insure that all the copper was. In the divalent state. When the samples were extracted in the normal manner, no noticeable difference in absorption was noted. 


\section{BIBLIOGRAP HY}

1. N. A. Ismailov and M. S. Shraiber, Farmatsia, 3, 1 (1938).

2. J. E. Meinhard and N. F. Hall, Anal, Chem,, 21, 185 (1949).

3. H. Seiler and M. Seiler, Helv. Chim. Acta, 43, 1939 $(1960)$.

4. H. Seiler, Helv. Chim. Acta, 45, 381 (1962).

5. E. J. Goller, J. Chem. Educ., 42, 442 (1965).

6. M. H. Hashmi, M. A. Shahid, A. A. Ayaz, F. R. Rafique, N. Hassan and A. S. Ad11, Anal. Chem•, 38, 1554 (1966).

7. K. Randerath, "Thin-Layer Chromatography," 2nd Ed., Academic Press, New York, 1966.

8. W. J. Frierson and M. J. Ammons, J. Chem. Educ, 27, $37(1950)$.

9. F. H. Pollard, J. F. W. McOmie and I. I. M. Elbeih, J. Chem. Soc., 1951, 466 .

10. M. Lederer, Nature, 163, 598 (1949).

11. W. A. Reeves and T. B. Crumpler, Anal. Chem., 23, $1576(1951)$

12. I. I. M. Elbeih, J. F. W. McOmie and F. H. Pollard, Discuss. Faraday Soc., I, 183 (1949).

13. M. Lederer, Anal. Chim. Acta, 5, 185 (1951).

14. F. H. Burstal1, G. Ro Davies, R P. Linstead and R. A. Wells, J. Chem., Soc., 1950, 516. 
15. F. H. Burstall, G. R. Davies, and R. A. Welis, Discuss. Faraday Soc., I, 179 (1949).

16. A. Lacourt, G. Sommereyna, E. Degeyndt, J. Baruh and J. Gillard, Nature, 163,999 (1949).

17. A. Lacourt, J. Gillard and M. Van der Walle, Nature $166,225(1950)$.

18. N. F. Kember and R. A. Wells, Analyst, 76, 579 (1951).

19. J. A. Lewis and J. M. Griffiths, Analyst, 76, 388 (1951).

20. R. I. Davies, Nature, 168, 834. (1951).

21. J. R. Bishop and H. Liebman, Nature, 167, 524 (1951).

22. A. Lacourt and P. Heyndryckx, Mikrochim. Acta, 1954, 630 .

23. E. Beerstecher, Anal. Chem., 22, 1200 (1950).

24. A. Lacourt and P. Heyndryckx, Nature, 176, 880 (1955).

25. C. Bergamini and W. Versorese, Anal. Chim. Acta, 10, 328 (1953).

26. R. H. Muller and D. L. Clegg, Anal. Chem., 23, 396 (1951).

27. R. J. Wiene, J. Chromatog., 1,166 (1958).

28. J. W. H. Lugg, J. Chromatog., 10, 272 (1963).

29. W. J. Frierson and W. J. Jones, Anal Chem., 23, 1447 (1951).

30. E. H. Winslow and H. A. Liebhafsky, Anal. Chem., 21, $1338(1948)$.

31. S. V. Vaeck, Anal. Chlm. Acta, 10, 48 (1954). 
32. R. B. Fischer and F. Vratny, Anal, Chim. Acta, 13, $588(1955)$.

33. M. M. Frodyma, R. W. Frei and D. J. Williams, J. Chromatog., 13, 61 (1964).

34. G. G. Stokes, Proc. Roy. Soc. London, 11, 545 (1862).

35. P. Kubelka and F. Munk, Z. tech. Physik., 12, 593 (1931).

36. P. Kubelka, J. Opt. Soc. Am., 38, 448 (1948).

37. D. B. Judd and G. Wyszecki, "Color In Science, Business, and Industry," 2nd Ed., John Wiley and Sons, Inc., New York, 1963.

38. G. W. Ingle, ASTM Bulletin No. 32, May (1942).

39. G. Kortum, Wo Braun and G. Herzog, Angew. Chem., Intern. Ed., 2, 333 (1963).

40. G. Kortum and H. Schottler, 2. Electrochem., 57, 353 (1953).

41. G. Kortum and G. Schreyer, Angew. Chem., 67, 694 (1955).

42. G. Kortum, Spectrochemica Acta suppl., 534 (1957).

43. G. Kortum and J. Voge1, Z. Phys. Chem., 18, 230 (1958).

44. G. Kortum, Trans. Faraday Soc., 58, 1624 (1962).

45. H. Zeitlin and A. Nímoto, Anal Chem., 31, 1167 (1959).

46. G. Kortum and J. Voge1, Z. Phys. Chem., 18, 110 (1958). 
47. R. W. Frei, "The Determination of Amino Acids by Reflectance Spectioscopy," Ph.D. Thesis, UnIversity of Hawail, 1965.

48. S. Buffagni and T. M. Dunn, J. Chem. Soc., 1961, 5105.

49. G. Kortum and G. Herzog, Z. Ana1. Chem., 190, 239 (1962).

50. G. Kortum, M. Kortum-Seiler, and S. D. Bailer, J. Phys. Chem., 66, 2439 (1962).

51. R. J. H. Clark, J. Lewis, D. J. Machin and R. S. Nyholm, J. Chem. Soc., 1963, 379.

52. H. Zeitlin and A. Nitmoto, Nature, 181, 1616 (1958).

53. H. Zeitlin and H. Goya, Nature, 183, 1041 (1959).

54. P. Anthony and H. Zeitlin, Nature, 187, 936 (1960).

55. H. Goya, J. L. T. Waugh and H. Zeitlin, J. Phys. Chem., 66, 1206 (1962).

56. H. Zeitiin, H. Goya and J. L. T. Waugh, Nature, 198, 178 (1963).

57. H. ZeItlin, N. Kondo and W. Jordon, J. Phys. Chem., So11ds, 25, 641 (1964).

58. J. J. Naughton, M. M. Frodyma and H. Zeitiin, Science, 125, 121 (1957).

59. J. J. Naughton, H. Zeitiin and M. M. Frodyma, J. Agr. Food Chem., 6, 933 (1958).

60. A. Bevenue and K. T. Williams, Arch. Blochem., 13, $291(1958)$.

61. A. Bevenue and K. T. W1111amsm J. Chromatog., 2, 199 
(1959).

62. K. Yamaguchi, S. Fukushima and M. Ito, J. Pharm. Soc. Japan, 25, 556 (1955).

63. V. T. Lieu and M. M. Frodyma, Talanta, 13, 1319 (1966).

64. C. A. Lermond and L. B. Rogers, Anal. Chem., 27, 340 (1955).

65. F. Pruckner, M. von der Schulenburg and G. Schwuttke, Naturwiss., 51, 45 (1951).

66. G. Schwuttke, Z. Angew. Phys., 5, 303 (1953).

67. M. M. Frodyma and R. W. Frel, J. Chromatog., 15, 501 (1964).

68. M. M. Frodyma and R. W. Frei, J. Chromatog., 17, 131 (1965).

69. M. M. Frodyma and V. T. Lieu, Anal. Chem., 39, 814 (1967).

70. G. Kortum, Angew. Chem., 50, 193 (1937).

71. C. F. Hiskey, Ana1. Chem, 21, 1440 (1949).

72. C. F. Hiskey, J. Rabinowitz and J. G. Young, Ana1. Chem., 22, 1464 (1950).

73. C. F. Hiskey and D. Firestone, Ana1. Chem., 24, 342 (1952).

74. C. N. Reilley and C. M. Crawford, Anal. Chem., 27, $716(1955)$.

75. D. F. Schutz and K. K. Tureklan, Geochim, and Cosmochim. Acta, 29, 259 (1965). 
76. M. G. Lai and H. V. Welss, Anal. Chem., 34, 1012 (1962).

77. T. Laevastu and T. G. Thompson, J. Conse11, Conse11 Perm. Intern. Exploration Mer, 21, 125 (1956).

78. T. G. Thompson and T. Laevastu, J. Marine Res,, 18, $189(1960)$.

79. D. E. Carritt, Anal. Chem., 25, 1927 (1953).

80. L. Alders, "Liqu-id-Liquid Extraction," Elsevier, New York, 1955.

81. G. H. Morrison and H. Freiser, "Solvent Extraction in Analytical Chemistry," John Wiley and Sons, Inc., New York, 1957 .

82. J. Stary, "The Solvent Extraction of Metal Chelates," Pergamon Press, New York, 1964.

83. H. Freiser, Ana1. Chem., 38, 131R (1966).

84. R. W. Frei and D. E. Ryan, Anal. Chim. Acta, 37, 187 ( 1967$)$.

85. E. B. Sande11, "Colorimetric Determination of Traces of Metals," 2nd Ed., Interscience, New York, 1950.

86. J. Hoste, Anal. Chim. Acta, 4, 23 (1950).

87. G. F. Smith and W. H. MeCurdy, Anal. Chem,, 24, 371 (1952).

88. F. D. Sneli and C. T. Snell, "Colorimetric Methods of Analysis," Vol. IIA, VanNostrand, Princeton, 1959.

89. R. Belcher, A. J. Nutten and W. I. Stephen, Analyst, 76, $378(1951)$. 
90. F. Feigl, "Spot Test," Vol. I, Elsevier, New York, 1954.

91. H. W. Harvey, "The Chemistry and Jertility of Sea Waters," Cambridge, London, 1963.

92. H. W. Harvey, "The Chemistry and Biology of Sea Water," Cambridge, London, 1945.

93. J. P. Riley and G. Skirrow, "Chemical Oceanography," Vo1. I, Academic Press, New York, 1965.

94. J. P. Riley and G. Skirrow, "Chemical Oceanography," Vo1. II, Academic Press, New York, 1965.

95. M. K. Tikhonov and V. K, Zhavoronkina, Soviet Oceanography, $3,22(1960)$.

96. J. D. H. Strickland and T. R. Parsons, Fisheries Research Board Canada, Bulletin, 125 (1960).

97. S. H. Fonselius and Fo Koroleff, Bull. Inst. Oceanogr. Monaco, 61, $1(1963)$.

98. D. C. Burrel1, Atomic Absorption Newsletter, (Perkin Elmer Corp.), 4, 309 (1965).

99. R. R. Brooks, Geochim. et Cosmochim. Acta, 29, 1369 (1965).

100. T.J. Chow and R. G. Robinson, J. Marine Res., 11, $124(1952)$.

101. J. P. Riley and P. Sinhaseni, Analyst, 83, 299 (1958).

102. A. P. Vinogradov, Sears Found. Marine Res., 2, 1 (1.963).

103. J. A. Wheat, U.S.-AEC, DP-879 (1964). 
104. N. D. Sylvester and L. H. Lampitt, Analyst, 60, 377 (1935).

105. H. Friedberg, Anal. Chem., 27, 305 (1955).

106. T. Moeller, "Inorganic Chemistry," John Wiley and Sons, New York, 1959.

107. R. R. Brooks, B. J. Resley and I. R. Kaplan, Anal. Chim. Acta, 38, 321 (1967). 